$\begin{array}{cc}\text { Türk Coğrafya Dergisi } \\ \text { Basılı ISSN 1302-5856 } & \text { Turkish Geographical Review } \\ & \text { www.tcd.org.tr }\end{array}$

\title{
Türkiye'de yağış ölçümü yapılan manuel-otomatik meteoroloji gözlem istasyonu verilerinin karşılaştırılması
}

\section{Comparison of manual-automatic meteorological station precipitation data in Turkey}

\author{
Erkan Yılmaz *a (D) Volkan Darende b (D) \\ ${ }^{a}$ Ankara Üniversitesi, Dil ve Tarih-Coğrafya Fakültesi, Coğrafya Bölümü, Ankara, Türkiye. \\ ${ }^{b}$ Meteoroloji Genel Müdürlügü, Ankara, Türkiye.
}

ORCID: E.Y. 0000-0002-3821-3648; V.D. 0000-0003-4055-7754

\section{BILGI / INFO}

Geliş/Received: 09.01.2021

Kabul/Accepted: 12.02 .2021

\section{Anahtar Kelimeler:}

Yağış ölçümü

manuel istasyon

otomatik meteoroloji gözlem istasyonu (OMGi)

Keywords:

Precipitation measurement manual meteorology observation station automatic weather observation station (AWOS)

*Sorumlu yazar/Corresponding author:

(E.Yılmaz)eryilmaz@ankara.edu.tr

DOI: $10.17211 /$ tcd. 834500

\section{Atff/Citation:}

Yılmaz, E., \& Darende, V. (2021). Türkiye'de yağış ölçümü yapılan manuel-otomatik meteoroloji gözlem istasyonu verilerinin karşılaştirılması. Türk Coğrafya Dergisi, (77), 53-66. https://doi.org/10.17211/tcd.834500

\section{ÖZ / ABSTRACT}

Türkiye'de 2000'li yıllarda otomatik meteoroloji gözlem istasyonları (OMGi) kurulmaya başlanmış ve istasyon sayısı yıllar içerisinde artmıştır. Bu istasyonlar, ya halihazırda manuel ölçümlerin yapıldığı istasyonlarla aynı yerde faaliyete geçerek, ya da daha önce hiç ölçüm yapılmayan yeni yerlerde kurularak işlerlik kazanmıştır. Geçmiş dönemde manuel ölçümlerin yapıldığı istasyonların bir kısmında OMGi'ler bir süre eşzamanlı çalıştııldıktan sonra manuel ölçümler sonlandırılmış, bir kısmında ise günümüze dek devam ettirilmiştir. OMGi'lerin kurulmasından sonra, insan tarafindan yapılan ölçümler ile makine ölçümleri şeklinde iki farklı ölçüm oluşmuş, çoğu zaman bu iki ölçüm birbirinden farklı değerler göstermiştir. Bu da iklim ve iklim değişimi çalışmaları için önemli bir problem olarak ortaya çıkmıştır. Bu çalışmada, Türkiye'de yağış ölçümü yapılan istasyonların bir envanteri yapılmış, OMGi ve manuel ölçüm yapılan istasyonlardaki (MANUEL) eşzamanlı ölçümler değerlendirilmiştir. íki ölçümün eşzamanlı yapıldığı aylık toplam yağışlar incelenmiş, iki veri arasındaki ilişkiler doğrusal regresyon ile analiz edilmiştir. Analizler neticesinde, regresyon sabitinin değerlendirilmesi ile düşük yağışlarda, OMGi istasyonlarının MANUEL istasyonlara göre daha hassas olduğu görülmüştür. Regresyon katsayısı değerlendirildiğinde ise, yağış miktarı arttğında MANUEL istasyonların daha fazla yağış kaydettiği ve OMGi'lerde daha düşük yağışlar ölçüldüğü görülmüştür. Neticede, OMGi ve MANUEL istasyon kullanılarak yapılacak analizlerde veri düzenlemesinin yapılması gerektiği, iki veri hassasiyetinin farklı olduğu ortaya çıkmıştır.

In Turkey, automatic weather observation stations (AWOS) were first established in the 2000s, and the number of the stations has increased over years. AWOSs started functioning either by operating at the same location where manual measurements were already in use or by establishing them in new locations where no measurements had been taken before. In some of the stations where manual measurements were carried out in the past, the manual measurements were terminated after the AWOSs were operated simultaneously for a while, and in some others, they have been continued operating. After the establishment of AWOSs, two different measurements occurred, as human and machine measurements, but most of the time, these two showed inconsistent values. This difference emerged as an important problem for climate and climate change studies. In this study, an inventory of precipitation measurements stations in Turkey is prepared and synchronous manual and AWOS measurements were evaluated. The monthly total precipitation, in which two measurements were made simultaneously, were examined, and the relationships between the two data were analyzed by linear regression. As a result of the analysis by evaluating the intercepts, it was observed that the AWOSs were more sensitive than manual stations in low precipitations. However, when the regression coefficient was evaluated, it was observed that when the amount of precipitation increased, manual stations recorded more precipitation than AWOSs. It is understood that the two data sensitivity are different, and a data should be calibrated before AWOS and MANUEL stations data are used in same time series. 


\section{Extended Abstract} Introduction

In this study, precipitation measurement stations in Turkey are evaluated and monthly total precipitation data measured at AWOS and MANUAL stations in the last 17 years are compared and analyzes on similarities and differences are carried out. AWOS-MANUAL station measurement sensitivities are tried to be determined and it was discussed whether two station data can be used as a continuation of the other when the AWOS data is to be extended to the past or MANUAL station data to the future. As a result of the study, it has been revealed that data standardization is required for the future climate and climate change studies.

\section{Method}

Linear regression analysis was used to compare the precipitation data of MANUAL and AWOSs. This analysis was carried out to determine the degree and properties of the relationship between two variables, one dependent and the other independent. While in some cases, one of these variables is the cause and the other is the result, in this study, both variables can be dependent or independent because it is currently not possible to say which measurement is correct or incorrect. However, as MANUAL measurements will be terminated, the AWOS data is the main variable characteristic for us. In the study, the constant in the regression was used to examine the precipitation value measured in AWOS when precipitation was not measured at the MANUEL station, and coefficient in the regression was used to determine the proportional differences between the two measurements.

\section{Results and Discussion}

As a result of the evaluation of meteorological stations in Turkey, almost 800 precipitation and mini meteorological stations with data of the previous period were identified. Intelligent stations (BK-A), while both the MANUAL station and AWOS were still measuring, it was found that only AWOS measurements continued in some others (BK-B). AWOS, on the other hand, are stations that were established after 2000, started to form a data archive, where the data frequency decreased to minutes and can characterize different geographical environments and operate unmanned.

Regression constant was used to compare MANUEL-AWOS station data in low precipitation months. This value refers the precipitation value measured by the y (dependent) variable, namely the AWOS station, in the month (when precipitation is not measured) when the $x$ variable data, namely MANU$\mathrm{AL}$ station, measures 0 . The difference is expected to be 0 in measurements made with different instruments used for the same variable, and the regression constants are required to be 0 as a result of the analysis of the MANUAL and AWOS stations data. However, in most cases, this value has been received as higher or lower than 0 . This indicates that the absolute 0 points of the two measurements vary.

The regression coefficient refers to the increase in precipitation at $x$, the AWOS, for every $1 \mathrm{~mm}$ increase of the MANUAL station measurement. If both stations make the same measurement, this value is expected to be 1 . If the value moves away from 1 , it shows that the ratio of two station measurements has changed and the difference in measurement has increased. A value greater than 1 indicates that the MANUAL station measures lower values than AWOS, and values smaller than 1 indicate that the MANUAL station records higher values than AWOS. In both types of stations, mostly coefficients lower than 1 occurred, and in general, MANUAL measurements were higher than those of AWS. Even if there is no natural trend, if the AWOS data is used as a continuation of MANU$\mathrm{AL}$ station data, it is understood that decrease in precipitation can be determine in areas where the regression constant is lower than 1, and increase in areas where it is higher than 1.

In the analyzes, the coefficients of determination were generally high and regression models could be practiced. In this case, it became possible to estimate AWOS data using MANUAL measurements, and vice versa. In this way, data standardization can be achieved and the differences between the two stations can be eliminated.

\section{Conclusions}

When MANUEL stations and AWOSs were operated similarly, although they measured similar precipitation values, there were differences between measurement values. There is a data standardization problem among these different measurements, and these problems need to be defined and resolved.

As a result of the regression analysis, the regression constants determined in BK-A and BK-B type stations were different from 0 . This shows that in low precipitation months (approximately 0-20 $\mathrm{mm}$ according to regression constants), two different stations measuring the same precipitation recorded different values and the absolute zeros were not the same. The reason for this difference needs to be determined.

Regression coefficients obtained as a result of the analyzes are far from 1 in both BK-A and BK-B type stations. This shows that there is no one-to-one relationship between MANUAL and AWOS, as in the regression constant. Overall, the regression coefficients lower than 1 indicates that MANUAL stations in the country make higher measurements compared to AWOS. These different measurements show that the AWOS data cannot be used as a continuation of the MANUAL station data. To eliminate this problem, different precipitation measurement causes should be analyzed separately at each station, AWOS data should be standardized in accordance with the MANUAL station data, and rainfall time series continuity should be ensured.

In some of the BK-A type stations, the coefficient of determination was lower, but overall, in Turkey, it was observed that the coefficient of determination increased depending on the increase of sample size. However, the coefficients of determination in BK-B type stations are low. This reduces the reliability of BK-B type station data. In general, the coefficients of determination increase depending on the $\mathrm{N}$ number. The values determined for stations with a high sample size give higher and more reliable results. Therefore, if possible, MANUAL measurements terminated by MGM at BK-B type stations should be restarted and regression parameters should be determined more reliably. Manual measurements at BK-A stations should be maintained for the continuity of the same data precision. 


\section{Giriş}

Türkiye'de meteorolojik gözlem ve ölçümler, 1925 yılında Ankara'da Rasadat-ı Cevviye adıyla faaliyete geçen enstitü tarafindan yapılmaya başlanmış, 1937 yılında Devlet Meteoroloji İşleri Genel Müdürlüğü kurulmasıyla (Meteroloji Genel Müdürlüğü, 2020a) kurumsallaşmış, atmosfer gözlem ve ölçümlerinin yapılması kanunen bu kuruma verilmiştir. Kurum adı 2011 yılında değiştirilmiş, Meteoroloji Genel Müdürlüğü (MGM) halini almış, faaliyet ve görevleri benzer şekilde devam etmiştir. Kurum tarafindan kurulan, başlangıçtan günümüze kadar yağış ölçümü yapan 2350 istasyon, ilk yıllarda sinoptik, büyük klima ve yağış istasyonları olarak nitelendirilmiş, 1950'li yıllarda küçük klima istasyonları da bunlara eklenmiştir. 1980 yılından sonra yağış istasyonları, mevcut rasat parklarına ilave ölçüm aletleri konularak küçük klima istasyonuna dönüştürülmüşlerdir. Tek personelle çalışan, sayıları 794 olan bu istasyonlar, 1980'li yılların ikinci yarısından itibaren personel yetersizliği nedeniyle kapanmaya başlamıştır. Büyük klimalar ise Türkiye iklim-meteoroloji literatürünün asıl kaynağını meydana getirmiş, veri eksikliği az olan, genellikle il ve büyük ilçe merkezi özelliğindeki yerleşmelerde kurulmuş istasyonlardır.

Türkiye, topografik özellikleri nedeniyle oldukça fazla ortam barındırmakta (Yılmaz ve Çiçek, 2016), tüm bu sahalarda meteorolojik verilerin kaydedilmesi oldukça zor olmakta, yağış da diğer meteorolojik olaylara göre daha önemli ve anlaşılması-modellenmesi zor bir değişken olarak karşımıza çıkmaktadır. MGM tarafindan ölçümü yapılan tüm değişkenlere ait veriler, ölçüm teknolojisi ve ekonomik imkanlara bağlı olarak farkIı aralıkta toplanmış ve kaydedilmiş, teknolojik gelişmeler ile iyileştirme-yenileştirmeler yapılmış, bu eksiklik-zorluğu ortadan kaldırmak amacıyla sürekli istasyon sayısını artırmış, 2016 yılından sonra yüksek dağ istasyonlarında yağış gözlemleri de yapılmaya, totalizatörlenden faydalanılmaya başlanmıştır. 1970 yılında havaalanlarına kurmaya başladığı havacılık amaçIı otomatik istasyonlardan sonra 2003 yılından itibaren iklim gözlemi amacı ile de otomatik meteoroloji gözlem istasyonları (OMGi) kurmaya başlamıştır. Bu istasyonların bir kısmı daha evvel yağış ya da küçük klimatoloji istasyonlarının kapatıldığı sahalara ya da daha evvel istasyon olmayan farklı yerlere kurulmuşlardır. OMGi'ler arızalı oldukları dönemlerde ölçüm yapamasa da otomatik gözlemlerin sürekli devam ettiği ve dakikalık veri setinin bulunduğu istasyonlardır. Bu istasyonların bir kısmı yeni kurulmuş birkaç yıllık rasat yapmış, bir kısmındaki veri uzunluğu 2020 yılı dahil edildiğinde 15 yılı geçmiştir. 2020 sonu yılı itibariyle bu istasyonların sayısı (büyük klimalar hariç) 1288'e ulaşmıştir. Genel bir değerlendirme yapıldığında (Şekil 1) Türkiye'de, geçmiş döneme ait verisi olan 800 'e yakın yağış ve küçük klima istasyonu bulunmakta, kapatılan bu istasyonların günlük veri arşivi bulunmaktadır. Büyük klimatoloji istasyonlarının veri arşivleri farklı özellik göstermekte, bir kısmında saatlik ölçümler de bulunmaktadır. OMGi'ler ise 2003 yılından sonra kurulan, veri arşivi oluşmaya başlayan, veri sıklığının dakikalara indiği, farklı coğrafi ortamları karakterize edebilen ve insansız çalışan istasyonlardır.

Illk OMGi'ler, büyük klima istasyonlarının rasat parklarına kurulmuş, manuel ölçüm yapan istasyonlarla (MANUEL) beraber çalıştırılmıştır. Daha sonraları farklı sahalara da OMGi'ler kurulmaya başlanmış ve bunların sayıları sürekli artmıştır (Meteroloji Genel Müdürlüğü, 2020b). 2011 yılından itibaren belirli dönemlerde her iki ölçümün birlikte yapıldığı istasyonlardaki manuel ölçümler sonlandırılmış, istasyonların çoğunda sadece OMGI ölçümleri yapılmaya başlanmıştr. Bu durum, veri toplama açısından farklı veri hassasiyetleri ortaya çıkarmıştır. OMGi'lerde kullanılan sensörler ile manuel ölçümlerde kullanılan sensörler arasındaki ölçüm hassasiyeti farklılığı, OMGi’lerde manuel ölçüme göre daha sık ölçüm yapılması, bu farklılıkların oluşmasında önemli etkenler olmuştur. Örneğin günlük ortalama sıcaklık, manuel ölçümlerle günde 3 değer ile hesaplanırken (bazı istasyonlarda saatlik ölçümlerden de yapılmıştır) OMGI'ler ile bu sayı 24'e (hatta 1440'a) çıkmıştır. Farklı bir durum yağış değişkeninde de gözlemlenmiş, her iki istasyonda ölçülen değerler arasında farklılıklar oluşmuştur. Eski rasat parklarına kurulan OMGi istasyonlarının manuel ölçümlerin devamı olması amaçlansa da bu farklılıklar, durumu karmaşık hale getirmiş, istasyon zaman serilerinde tutarsızlıklar oluşmuştur. Bu durum, günümüzde etkisini sıkça hissettiğimiz iklim değişikliğiyle de birleştiğinde, araştırmacıların veri kullanımı hakkında çekinceleri oluşmuş, değişim ya da eğilimlerin neden kaynaklandığı hakkında farklı iki durum ortaya çıkmıştır. Farklılığın doğal mı, ölçüm farkında mı kaynaklandığı hakkında soru işaretleri oluşmaya başlamış, iki verinin birbirinin devamı niteliğinde olan çalışmalardan kaçınılmıştır. Bu karmaşa-belirsizlik, veri standardizasyonu eksikliğinin giderilmesi gerekmektedir. Farklı hassasiyette istasyon verilerinin kullanılması, gerçek eğilim değerlerini değiştirecek, gerçekteki değer ve eğilimler ölçüm farklılığına bağlı olarak değerlendirilebilecektir.

Klimatolojik-meteorolojik araştırmalardan doğru sonuçlar elde edilebilmesi, tüm araştırmalarda olduğu gibi kullanılan verinin

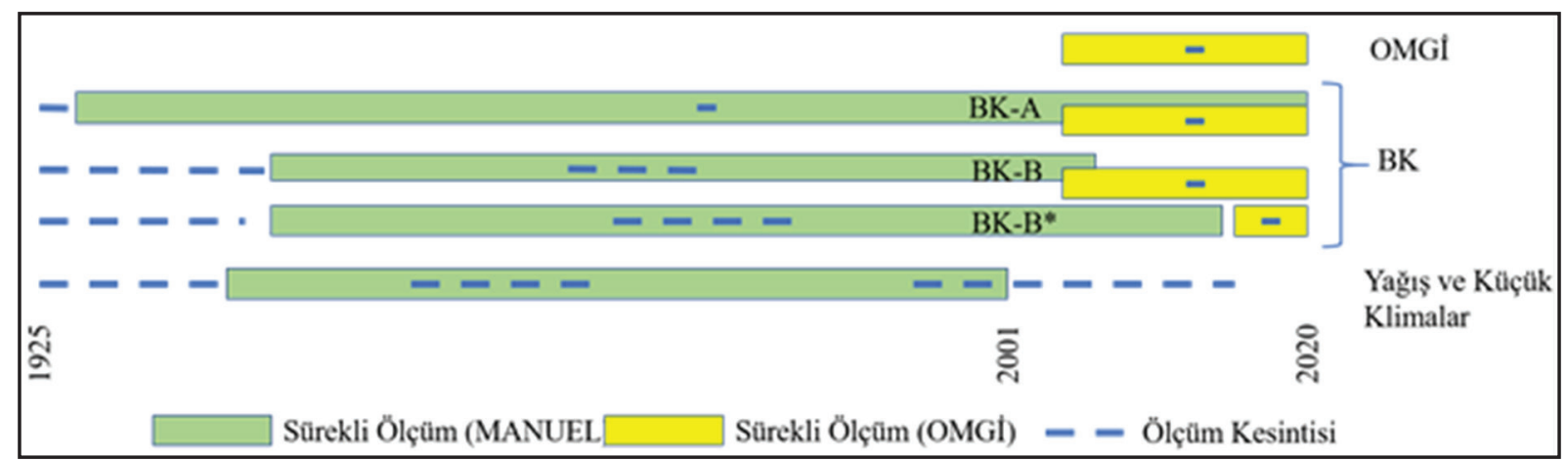

Şekil 1. İstasyon tipleri ve ölçüm dönemleri.

Figure 1. Station types and measurement periods. 
doğru, güvenilir, tutarlı, yansız elde edilmesine-ölçülmesine bağlıdır. Bir ölçme işlemi aynı koşullarda tekrarlandığında, ölçüm hatası yok ise aynı değeri vermelidir (Sencer \& Sencer, 1978). Klimatolojik çalışmaların güvenilirliğinin sağlanabilmesi aynı kalitedeki ölçüm-gözlemlerin devamlılığının sağlanması gerekmektedir. Bir noktada yapılan ölçümde, alet değiştirildiğinde, yeni ve eski ölçüm aleti bir süre birlikte çalıştırılmakta, iki alet hassasiyeti ve ölçümleri arasındaki farklılıklar belirlenmek durumundadır. Bu süre değişmekte bazı değişkenlerde iki mevsim ile yetinilirken, yağış için 5 yıl eşzamanlı ölçümler önerilmektedir (Akçakaya vd., 2013).

Bu çalışmada incelenen ve değerlendirilen büyük klima istasyonları, yağış verisi açısından iki grupta toplanmış, bunlar BK-A ve BK-B tipi olarak sınıflandırılmıştır (Şekil 2). BK-A tipi istasyonlar, 2003 yılından sonra farklı yıllarda OMGi'ye dönüştürülmüş ve hem MANUEL hem de OMGi istasyonu birlikte çalıştırılmış, eşzamanlı ölçümlerin günümüzde devam ettiği istasyonlardır. 102 adet olan bu istasyonlar Türkiye iklim literatürünün de kaynak istasyonları niteliğindedir ve Türkiye ile ilgili önemli iklim eğilim çalışmaları bu istasyon verileri ile yapılmıştır (Çiçek, 2001; Dadaser-Çelik vd., 2016; Erlat, 1996; İçel \& Ataol, 2014; Türkeş, 2003; Türkeş, Sümer \& Kiliç, 2002; Türkeş \& Tatli, 2009; Türkeş, 1996). BK-B olarak adlandırılan 166 adet istasyon, farklı özellikler göstermektedir. Bu noktalarda ya manuel ölçümler sonlandırıldıktan belli bir süre sonra OMGi kurulmuş (BK-B*, 13 adet) ya da OMGi kurulduktan belli bir müddet sonra manuel ölçümler sonlandırılmıştır (BK-B, 153 adet). Bu istasyonlar verileri de birçok iklim çalışmasında kullanılmış (Koç \& Keskin, 2001; Tekin, Tatlı \& Koç, 2018; Toros, 2012; Yılmaz, 2018), veri eksikliklerinin BK-A tipine göre daha fazla olduğu görülmüştür.

Yukarıda sayılan gerekçeler, MANUEL istasyonun devamı niteliğinde olan OMGi verilerinin MANEUL ölçümlerle olan farkIılıklarının giderilmesi gerektiğini ortaya koymakta, Türkiye'de bu yönde bir çalışma da bulunmamaktadır. Bu çalışmada, son 17 yıl içerisinde OMGI ve MANUEL istasyonlarda eşzaman-
Iı ölçülen aylık toplam yağış verileri karşılaştırılmış, benzerlik ve farklılıklar üzerine analizler yapılmıştır. Çalışma sonucunda bundan sonra yapılacak iklim ve iklim değişikliği çalışmaları için veri standardizasyonunun gerektiği ortaya koyulmuştur.

\section{Veri ve Yöntem}

Çalışmada, MGM'den 268 (102 BK-A+153 BK-B +13 BK-B*) büyük klima istasyonlarına ait aylık toplam yağış verileri istenmiş ve eşzamanlı ölçümler değerlendirilmiştir. Eşzamanlı ölçüm yapan OMGi ve MANUEL istasyon verileri incelenmiş, bazı aylarda OMGi $100 \mathrm{~mm}$ civarında ölçerken MANUEL istasyon 5 $\mathrm{mm}$ ölçtüğü, bazı aylarda ise tam tersi durumlar olduğu görülmüştür. Yine bazı aylarda OMGi $3 \mathrm{~mm}$ ölçerken, MANUEL istasyon $0,1 \mathrm{~mm}$ ölçmüş, farklı değerlerin yoğunlukta olduğu görülmüştür. Bu türden durumların, kayıt eksikliği-yanlışlığından kaynaklandığı düşünülmüş, farklı ölçüm değerleri arasında büyük fark (\% 50'den fazla) var ise bu ölçümler analiz dışında bırakılmıştır. İstasyon adları yerine karışıklıkların engellenmesi amacıyla kodları kullanılmıştır.

İki tür verinin karşılaştırılması amacıyla doğrusal regresyon analizi kullanılmıştır. Bu analiz, biri bağımlı diğeri bağımsız iki değişken arasındaki ilişkinin derecesi ve özelliklerini belirlemek için kullanılmaktadır. Bazı durumlarda bu değişkenlerden biri sebep diğeri sonuç olurken, bu çalışmada, her iki değişken de bağımlı ya da bağımsız olabilecek bir durum sergilemektedir. Çünkü hangi ölçümün doğru hangisinin hatalı olduğunu söylemek şu an mümkün değildir. Buna rağmen, MANUEL ölçümler sonlandırılacağı için, OMGi verileri bağımlı değişken olarak kullanılmıştir.

Doğrusal regresyon, eşitlik 1 ile ifade edilmekte (Weisberg, 2015 , s. 22), bu çalışmada $\hat{y}$ değeri OMGi, $x$ değeri ise MANUEL istasyon verisi olarak kullanılmıştır. $\beta_{0}$ ve $\beta_{1}$ katsayıları en küçük kareler yöntemi ile tahmin edilmekte bu işlem ise matrislerle ya da cebirsel işlemler de kullanılabilmektedir. Eşitlik 1'de; $\beta_{0}$, regresyon sabitini göstermekte, $x$ değişkeninin $30^{\circ} \mathrm{E}$

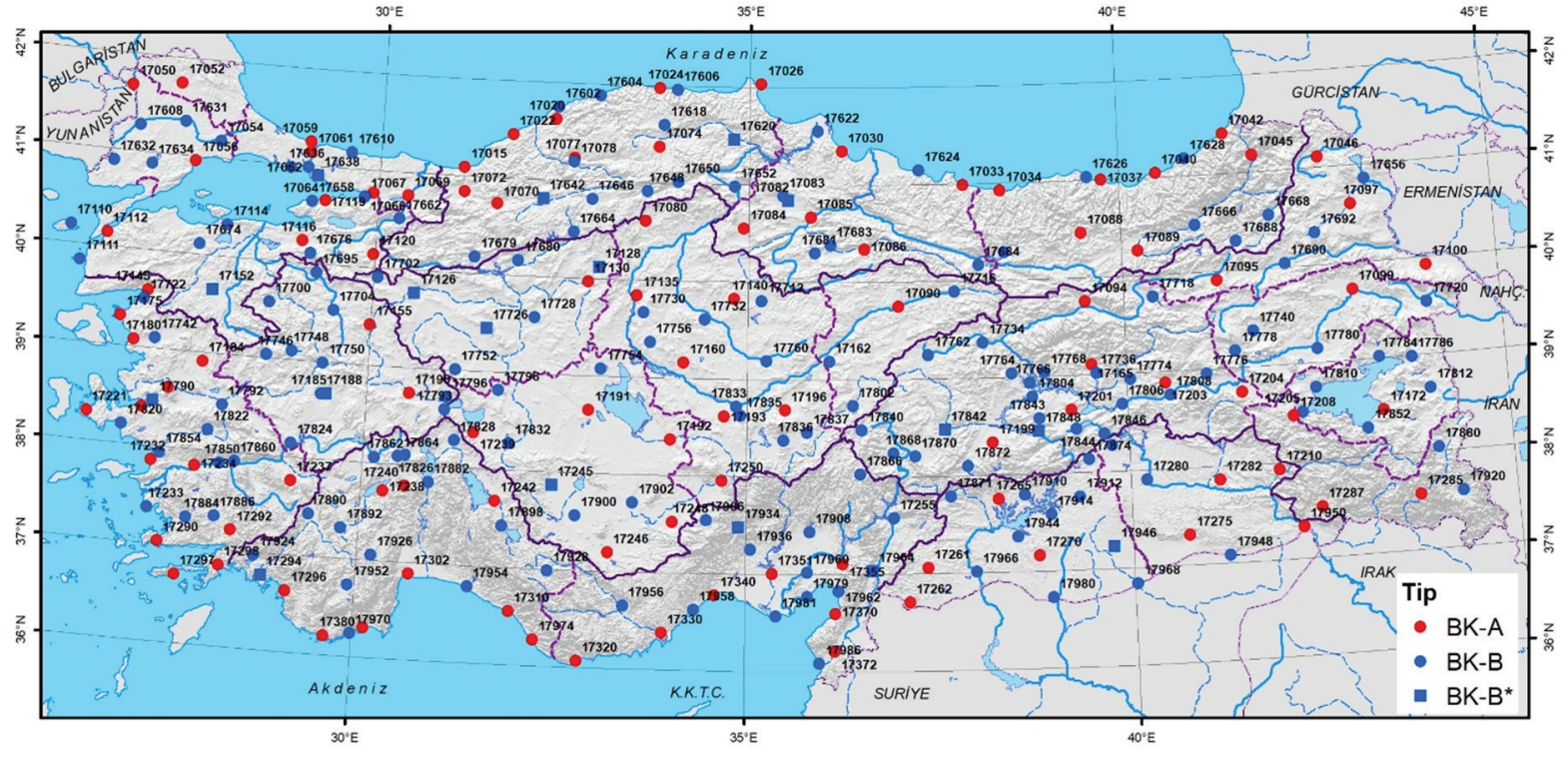

Şekil 2. BK-A ve BK-B tip meteoroloji istasyonlarının konumları.

Figure 2. Locations of $B K-A$ and $B K-B$ type meteorology stations. 


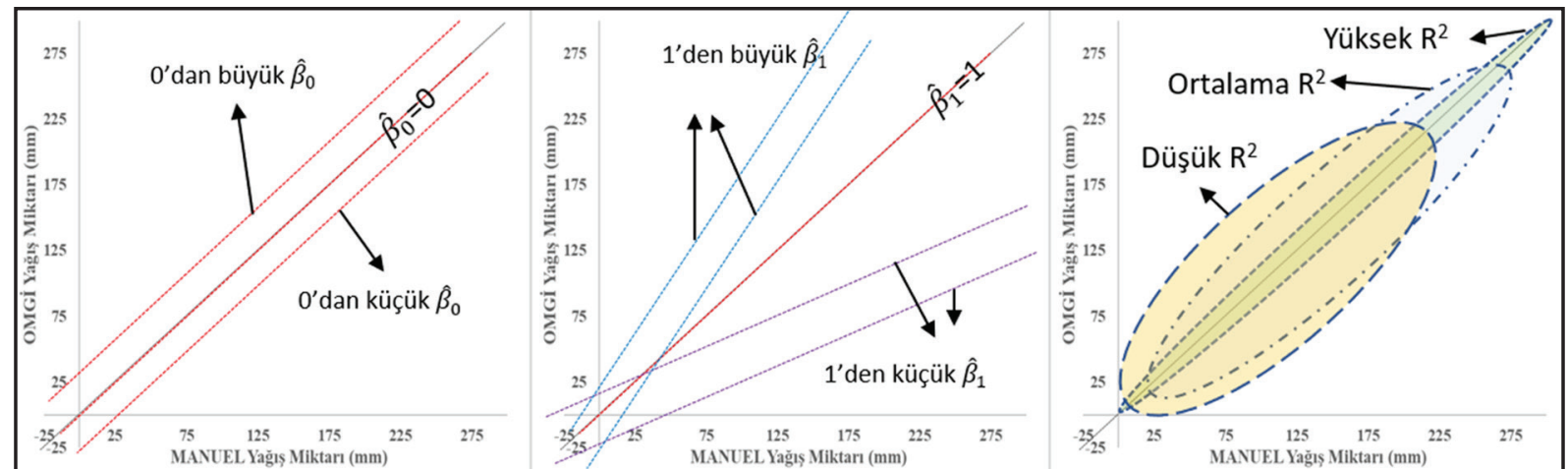

Şekil 3. Farklı regresyon durumları.

Figure 3. Different regression cases.

0 olması durumunda, $y$ değişkeninin alacağı değeri ifade etmektedir (Gürtan, 1979, ss. 515-572). Eşitlik 2 ile elde edilen regresyon sabiti negatif ya da pozitif olduğunda, $y$ değişkeninin-ölçümünün 0 noktasının $x$ değişkeni-ölçümünden farklı olduğu (Şekil 3) anlaşılmaktadır.

$$
\begin{aligned}
& \hat{y}=\hat{\beta}_{0}+\hat{\beta}_{1} x \\
& \hat{\beta}_{0}=\bar{y}-b \bar{x}
\end{aligned}
$$

$\beta_{1}$ değeri regresyon katsayısı (regresyon eğimi) olarak adlandırılmakta, $x$ değişkenindeki 1 birimlik artış ya da azalışın, y değişkeninde oluşturacağı değişimi ifade etmekte ve eşitlik 3 ile hesap edilmektedir. $\beta_{1}$ değeri 1'den düşük olduğunda, $\mathrm{x}$ ölçümünün y ölçümüne göre daha büyük, tersi durumda ise daha düşük değer ölçtüğü anlaşılmaktadır (Şekil 3).

$$
\hat{\beta}_{1}=\frac{\sum(y-\bar{y})(x-\bar{x})}{\sum(x-\bar{x})^{2}}
$$

Gözlenen $(y)$ ve hesap edilen $(\hat{y})$ değerleri arasındaki ilişkiye bağlı olarak belirleme katsayısı $\left(\mathrm{R}^{2}\right)$ hesap edilmektedir (Eşitlik 4). Belirleme katsayısı 0 ile 1 arasında değişen değerler alabilmekte ve iki değişkenin birbirini açıklama oranını ifade etmektedir. İki değişken-ölçüm arasında farklar düşük olduğunda belirlenme katsayısı 1'e yaklaşmaktadır (Şekil 3).

$$
R^{2}=\frac{\sum_{i=1}^{n}\left(\widehat{y_{i}}-\bar{y}\right)^{2}}{\sum_{i=1}^{n}\left(y_{i}-\bar{y}\right)^{2}}
$$

$\beta_{0}$ ve $\beta_{1}$ değerlerinin hipotez testleri $t$ dağılımına göre yapılmaktadır (Alpar, 2003, ss. 405-480). Regresyon denkleminin standart hatası $(s)$ eşitlik 5 kullanılarak hesaplandığında, regresyon sabiti için eşitlik 6 ve 7 kullanılarak t değeri elde edilmekte ve hipotez testi $n-k$ serbestlik dereceli t dağılımına göre yapılmaktadır.

$$
\begin{gathered}
s=\sqrt{\frac{\sum_{1}^{n}(y-\hat{y})^{2}}{n-2}} \\
s_{\hat{\beta}_{0}}=s \sqrt{\frac{1}{n}+\frac{\bar{x}^{2}}{\sum_{i=1}^{n}\left(x_{i}-\bar{x}\right)^{2}}}
\end{gathered}
$$

$$
t_{\hat{\beta}_{0}}=\frac{\hat{\beta}_{0}}{s_{\hat{\beta}_{0}}}
$$

Regresyon katsayısına ait t değeri eşitlik 8 ve 9 kullanılarak elde edilmekte, hipotez testi yine $n-k$ serbestlik dereceli $t$ dağıımına göre yapılmaktadır.

$$
\begin{gathered}
s_{\hat{\beta}_{1}}=\frac{\mathrm{s}}{\sqrt{\sum_{i=1}^{n}\left(x_{i}-\bar{x}\right)^{2}}} \\
t_{\hat{\beta}_{1}}=\frac{\hat{\beta}_{1}}{s_{\hat{\beta}_{1}}}
\end{gathered}
$$

Belirleme katsayısının hipotez testi $\mathrm{F}$ testi ile yapılmakta, $\mathrm{k}$ değişken sayısını ifade etmek üzere, eşitlik 10 ile elde edilen $F$ değeri, $k-1$ ve $n-k$ serbestlik dereceli $F$ dağılımına göre değerlendirilmektedir.

$$
F=\frac{\sum_{i=1}^{n}\left(\widehat{y_{i}}-\bar{y}\right)^{2}}{\frac{\sum_{1}^{n}(y-\hat{y})^{2}}{n-k}}
$$

\section{Bulgular ve Tartışma}

Bu kısımda, BK-A ve BK-B tipi istasyonlarda, MANUEL ve OMGi istasyonlarının birlikte ölçüm yaptı̆ı döneme ilişkin aylık toplam yağış verileri değerlendirilmiş, iki ölçüm arasındaki ilişkiler belirlenmiş, haritalanarak yorumlanmıştır. iliş̧kiler regresyon analizi ile incelenmiş, analiz sonucunda elde edilen regresyon sabitleri $\left(\beta_{0}\right)$, regresyon katsayıları $\left(\beta_{1}\right)$ ve belirleme katsayıları $\left(R_{2}\right)$ ile analizde kullanılan örneklem büyüklükleri $(N)$ değerlendirilmiş, bu değerlerin dağılışı ortaya koyulmuştur.

\subsection{Regresyon Sabitlerinin Dağılışı}

Analizler sonucunda hem MANUEL hem de OMGi istasyon ölçümlerinin devam ettiği BK-A tipi istasyonlar için elde edilen regresyon sabitleri $-4,36$ ile 10.08 arasında değişmiş, 40 istasyonda negatif, geri kalan 62 istasyonda ise pozitif sabitler elde edilmiştir (Şekil 4). Regresyon sabitleri, Kıyı Ege, Göller Bölgesi, Orta, Doğu Karadeniz ile Yukarı Fırat ve Adana Bölümü istasyonlarında negatif, diğer sahalarda genel olarak po- 


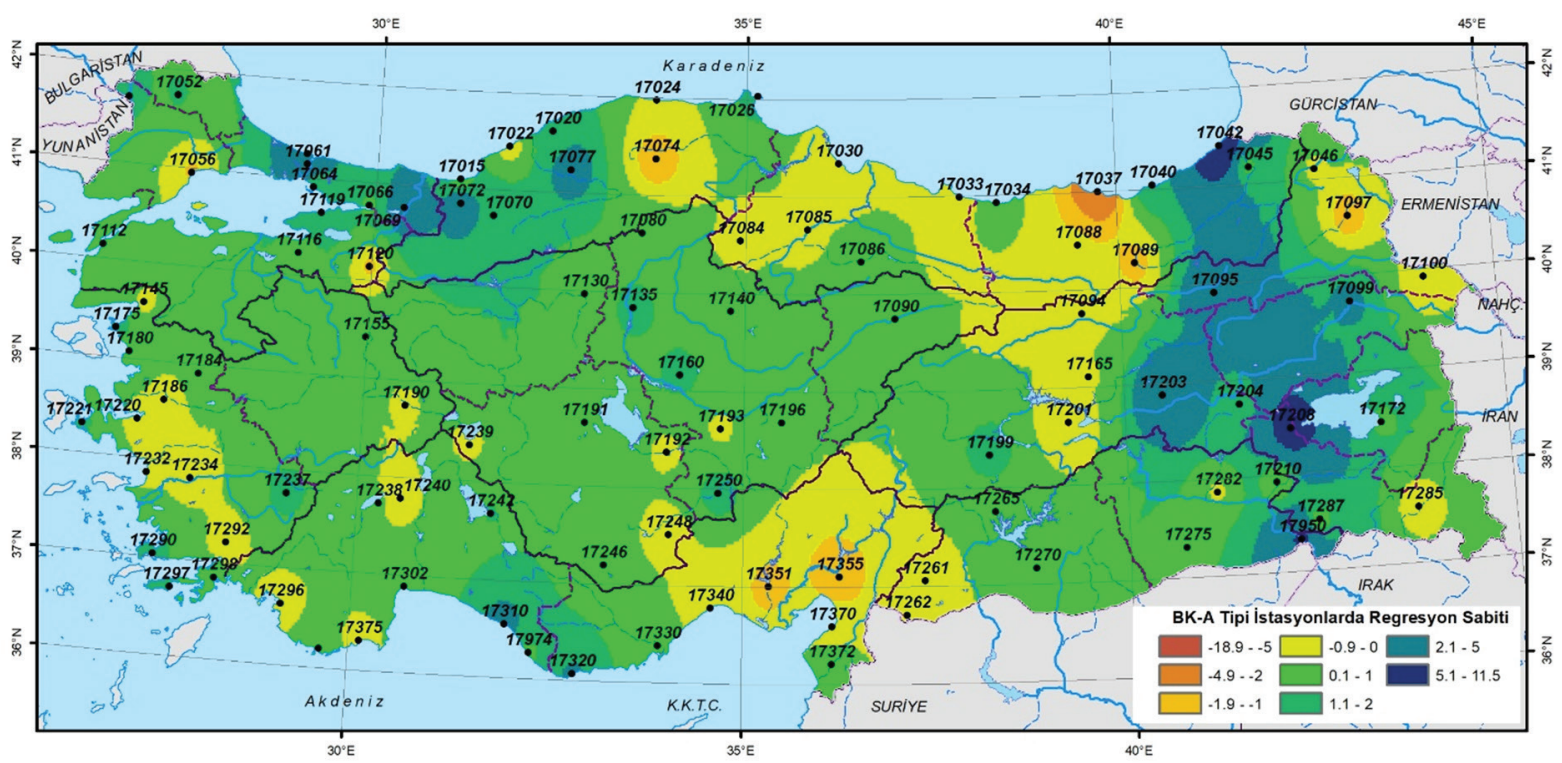

Şekil 4. BK-A tipi istasyonlarda regresyon sabiti dağılışı.

Figure 4. Intercept distribution at BK-A type stations.

zitif olarak hesap edilmiştir. BK-A tipi istasyonların regresyon sabitinin hipotez testi sonucunda sadece on istasyonunun (17069-Sakarya, 17160-Kırşehir,17059-Kilyos, 17061-Sarıyer, 17074-Kastamonu, 17950-Cizre, 17095-Erzurum, 17072-Düzce, 17042-Hope, 17089-Bayburt) t değeri $p<0,05$ seviyesinde anlamlı çıkmıştır.

MANUEL ölçümlerin OMGI istasyonuyla bir süre devam ettirildikten sonra sonlandırıldığı BK-B tipi istasyonlarda, eşzamanlı ölçümlerin alındığı aylık toplam yağışların regresyon analizi sonucunda elde edilen regresyon sabitleri -18,9 ile 11,5 arasında değişmiş, değerlerin 58'i negatif 95'i ise pozitif olarak hesaplanmıştır. Değerler, Güneydoğu, Doğu ve İç Anadolu Bölgeleri ile Batı Karadeniz Bölümünde negatif, Karadeniz, Marmara, Ege ve Akdeniz Bölgeleri ile İç Anadolu Bölgesi'nin doğusu ve Türkiye'nin doğu sınırı çevresindeki istasyonlarda ise pozitif olarak hesap edilmiştir (Şekil 5). Regresyon katsayılarının hipotez testleri sonucunda, sadece iki istasyonda (17722-Burhaniye, 17618-Devrekani) $p<0,05$ seviyesinde anlamlılı belir- lenmiş, diğer istasyonların hipotez testi sonuçları istatistiksel olarak anlamlı çıkmamıştır.

Elde edilen regresyon sabitlerinin dağılımı incelendiğinde hem BK-A hem de BK-B tipi istasyonlara 0 çevresinde frekans değerinin (istasyon sayısı) arttı̆ı, BK-B tipi istasyonlarda nispeten simetrik bir dağılım ortaya çıkarken, BK-A tipi istasyonlarda sağa çarpık bir dağılım oluştuğu görülmektedir (Şekil 6).

BK-A tipi istasyonlarda en yüksek regresyon sabiti 17042 (Hopa), en düşük ise 17037 (Trabzon) istasyonunda belirlenmiştir (Şekil 7). Benzer şekilde, 17208 (Bitlis), 17950 (Cizre) ve 17203 (Bingöl)'de 4'ten büyük, 17074 (Kastamonu) istasyonunda ise 2'den küçük regresyon sabitleri elde edilmiştir (Şekil 5). 0'a en yakın regresyon sabiti 17210 (Siirt) istasyonunda çıkmıştir.

BK-B tipi istasyonlarda regresyon sabiti en düşük 17802 (PInarbaşı) en yüksek 17628 (Pazar) istasyonunda belirlenmiştir (Şekil 7). 17774 (Karakoçan) ve 17874 (Çermik) istasyonların-

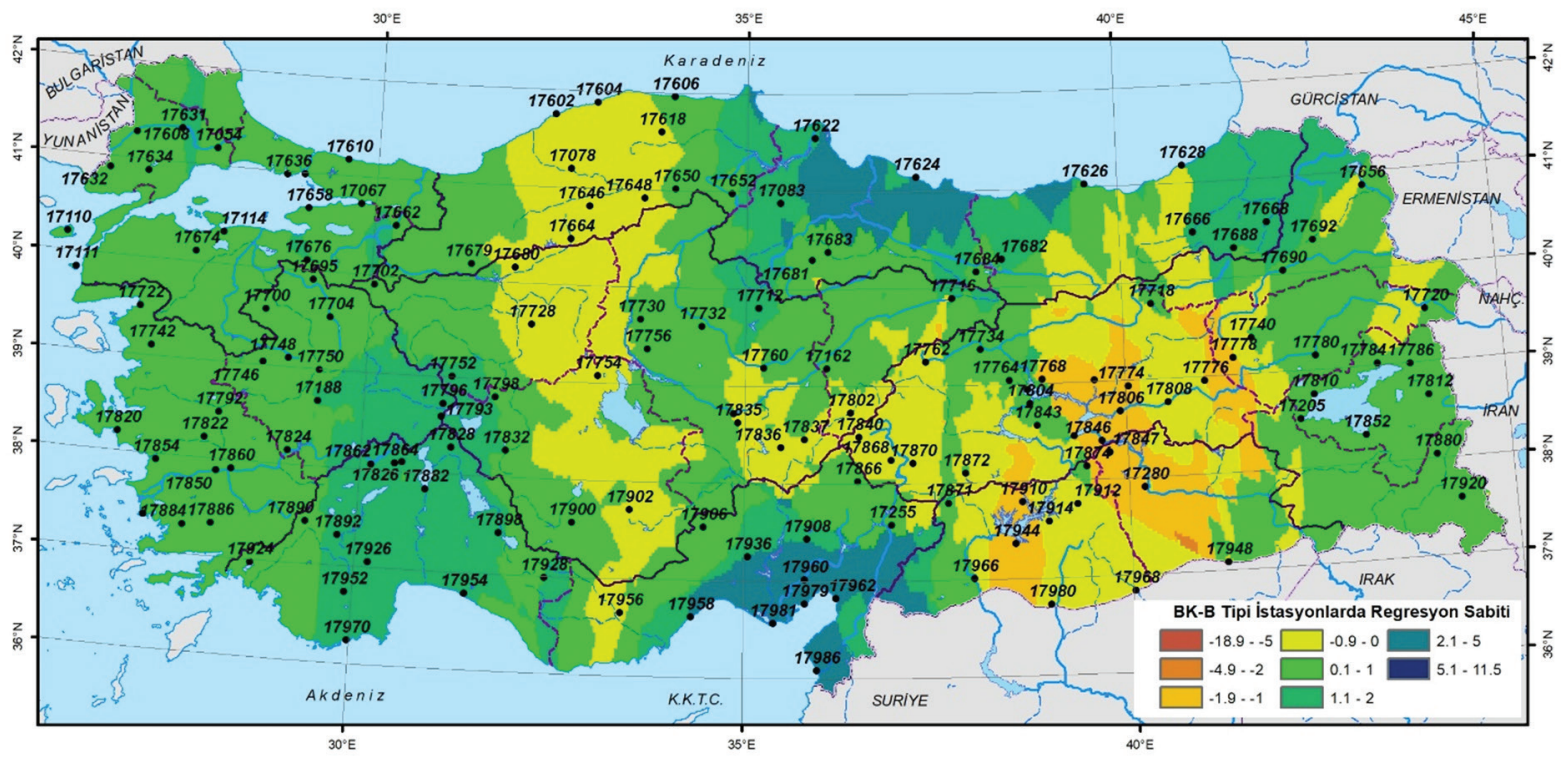

Şekil 5. BK-B tipi istasyonlarda regresyon sabiti dağılışı.

Figure 5. Intercept distribution at BK-B type stations. 

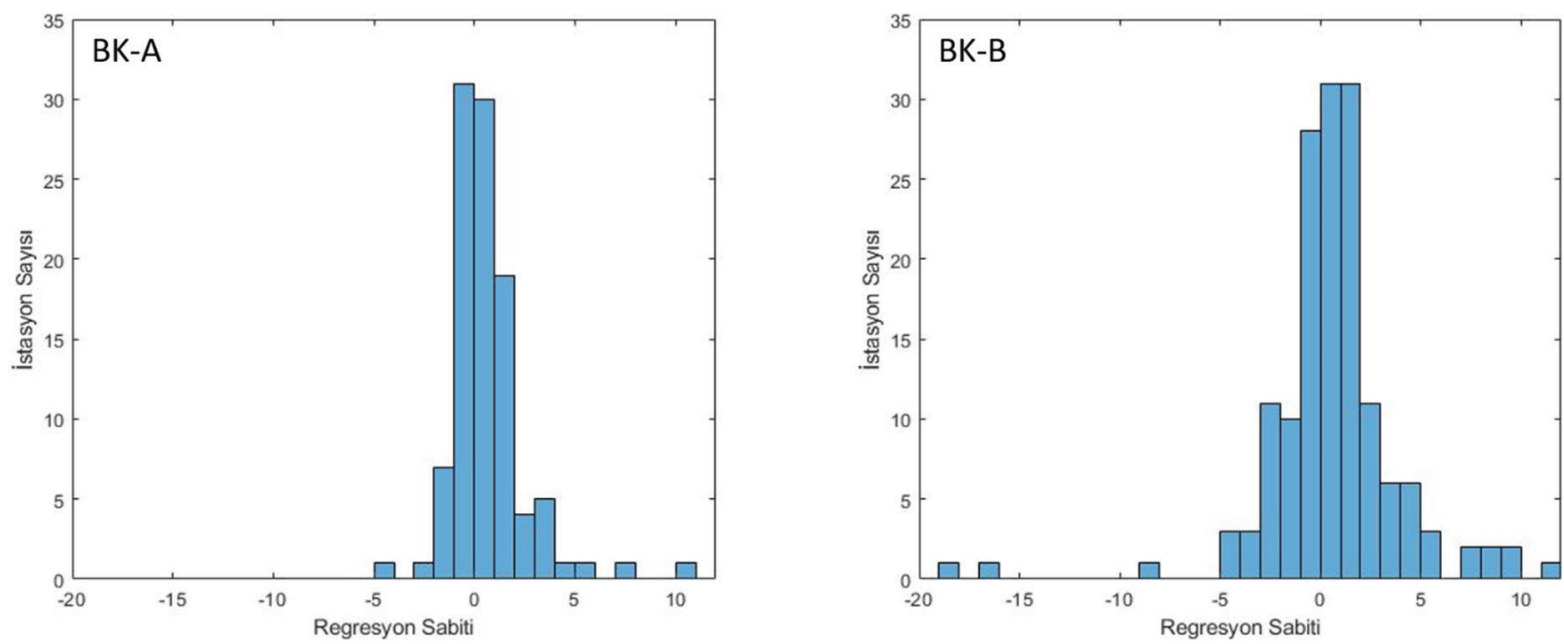

Şekil 6. BK-A, BK-B tipi istasyonlarda regresyon sabiti dağılımı.

Figure 6. Distribution of intercept at $B K-A$ and $B K-B$ type stations.

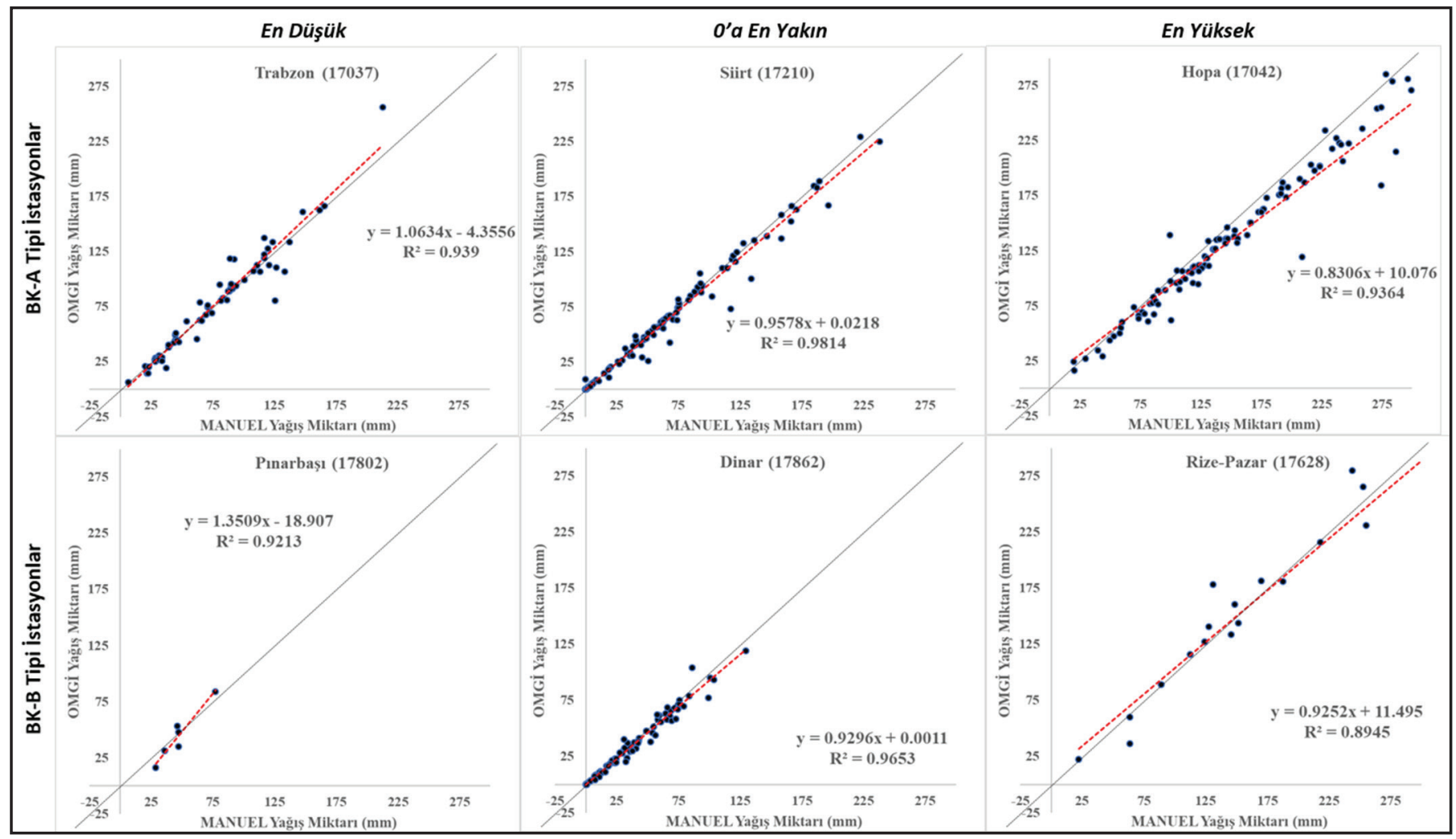

Şekil 7. BK-A ve BK-B tipi istasyonlarda, 0’a en yakın, en yüksek ve en düşük regresyon sabitine sahip istasyonların regresyon modelleri ve grafikleri (Kırmız kesikli çizgi regresyon doğrusunu, siyah sürekli doğru ise $45^{\prime}$ lik eğimi, 0 regresyon sabitini temsil etmektedir).

Figure 7. Regression models and graphs of stations with the closest to 0 , highest and lowest regression constant at BK-A and BK-B type stations (Red dashed line represents regression line, black continuous line represents 45 degrees slope $=0$ regression constant).

da 8'den düşük, 17986 (Samandağ), 17960 (Ceyhan), 17962 (Dörtyol) ve 17624 (Ünye) istasyonlarında ise 8'den büyük sabitler elde edilmiştir (Şekil 5). 17862 (Dinar) istasyonunda ise 0 'a en yakın regresyon sabiti belirlenmiştir.

Regresyon sabiti, düşük yağışlı aylardaki MANUEL-OMGi istasyon verilerini karşılaştırmak amacıyla kullanılabilecek bir istatistiktir. Bu değer, $x$ değişkeninin yani MANUEL istasyon verisinin 0 yağış ölçümü yaptı̆̆ı ayda (yağış ölçülmediğinde), y (bağımlı) değişkeninin yani OMGi istasyonunun ölçtüğü yağış değerini ifade etmektedir. Aynı değişkeni ölçen farklı ölçüm aletleri ile yapılan ölçümlerde farkın 0 olması beklenmekte, MANUEL ve OMGi istasyonları verilerinin analizi sonucunda regresyon sabitlerinin de 0 olması istenmektedir. Buna rağ- men istasyonların büyük bir bölümünde bu değer 0'dan yüksek ya da düşük değerler elde edilmiştir. Bu durum, iki farklı ölçümün mutlak 0 noktalarının değiştiğini, ölçümler arasında farklııklar olduğunu göstermektedir. Bu farklılığa bağlı olarak, regresyon sabiti 0'dan düşük sahalarda, OMGi istasyonlarında düşük yağışların kaydedilmeme durumunun ortaya çıktığı, regresyon sabiti 0'dan büyük sahalarda ise MANUEL istasyonda kaydedilmeyen düşük yağışların OMGi'de kaydedilebildiği anlaşılmaktadır.

\subsection{Regresyon Katsayılarının Dağılışı}

Regresyon analizleri sonucunda BK-A tipi istasyonlarda regresyon katsayılarının 0,74 ile 1,06 arasında değiştiği belirlen- 


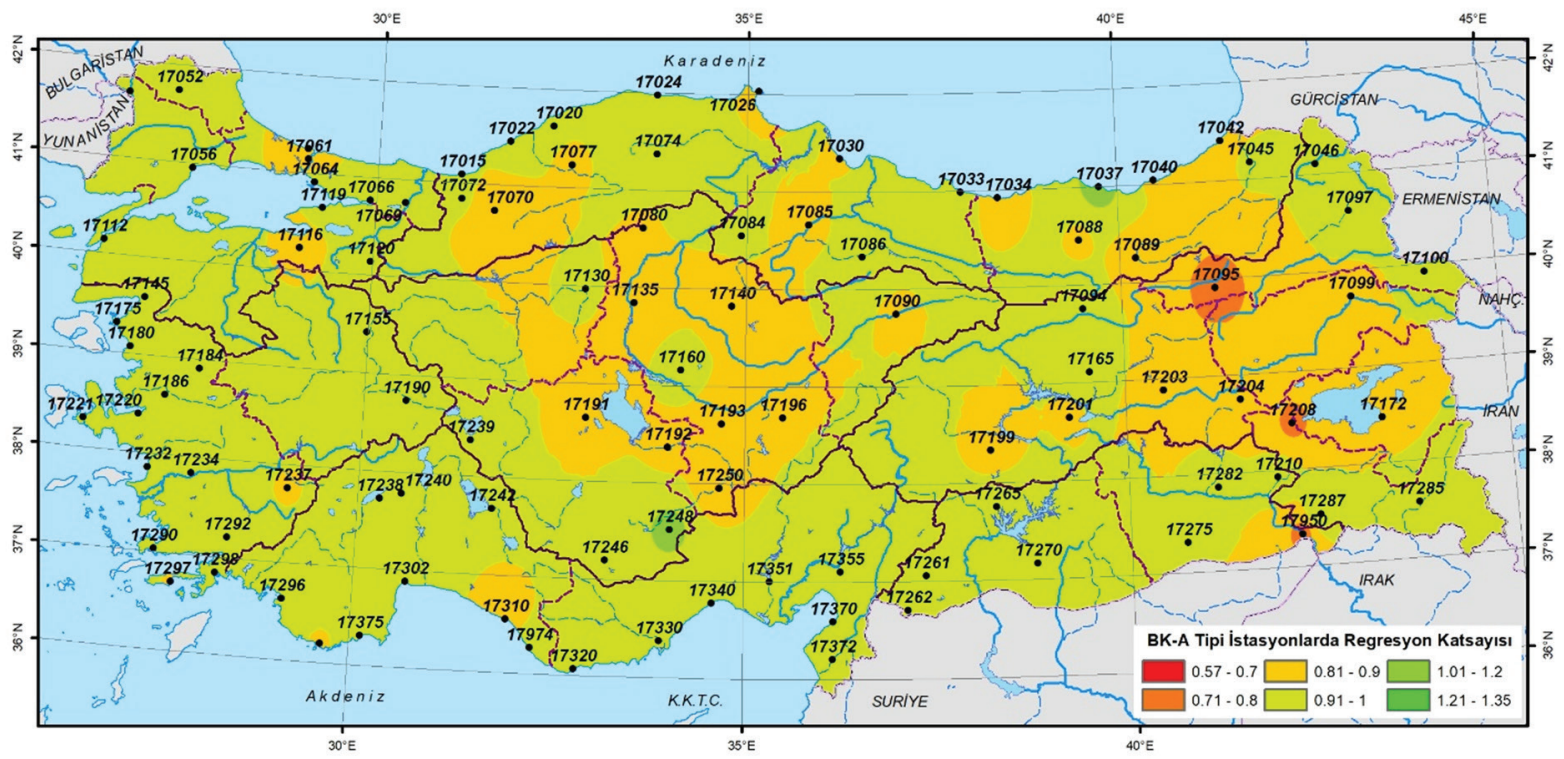

Şekil 8. Türkiye'de BK-A tipi istasyonların regresyon katsayısı dağılışı.

Figure 8. Regression coefficient distribution at BK-A type stations in Turkey.

miştir (Şekil 8). Ortalama regresyon katsayısının 0,9182 olarak belirlendiği bu analizlerde, 100 istasyonda 1 'in altında, 2 istasyonda ise 1'ün üzerinde regresyon katsayısı hesaplanmıştır. Değerler, genel olarak Doğu ve İç Anadolu Bölgesi'nde düşük çıkmıştır. İstasyonların büyük bölümünde 1'den düşük katsayılar elde edilmesi, BK-A tipi istasyonlardaki MANEUL ölçümlerinin, OMGi ölçümlerine göre yüksek olduğunu göstermektedir.

BK-B tipi istasyon verilerinin analizi sonucunda regresyon katsayılarının 0,56 ile 1,35 arasında değiştiği belirlenmiş, ortalama olarak ise 0,9177 değeri elde edilmiştir. Katsayılar, Doğu ve İç Anadolu Bölgeleri ile İç Ege, Antalya ve Orta Karadeniz Bölümlerinde 0,9'un altında, Orta ve Yukarı Fırat Bölümlerinde ise 1,2 'den yüksek olarak hesap edilmiştir (Şekil 9). Analizlerde, istasyonların 133'ünde 1'den düşük, 20'sinde 1'den yüksek katsayılar elde edilmiştir. Bu sayılara bakarak, BK-B tipi istasyonların da BK-A tipte olduğu gibi, MANUEL ölçümlerin, OMGi ölçümlerine göre yüksek değerler kaydettiği görülmektedir.
Analizler sonucu elde edilen regresyon katsayılarının dağılımı incelendiğinde, BK-A tipi istasyonlarda sola çarpık, bir durum olduğu, 1'den yüksek değerin az sayıda belirlendiği, BK-B tipi istasyonlarda ise daha simetrik bir dağılım oluştuğu anlaşılmaktadır (Şekil 10). İki tip istasyonda da regresyon katsayısı ortalaması birbirine çok yakın çıkmıştır.

BK-A tipi istasyonlarda en düşük regresyon katsayısı 17095 (Erzurum), en yüksek ise 17037 (Trabzon) istasyonda belirlenmiştir (Şekil 11). 1'e en yakın regresyon katsayısı 17287 (Şırnak) istasyonunda çıkmıştır. BK-B tipi istasyonlarda, en düşük regresyon katsayısı 17712 (Sorgun), en yüksek ise 17802 (Pınarbaşı) istasyonunda çıkarken, 1'e en yakın değer 17886 (Yatağan) istasyonunda belirlenmiştir (Şekil 11).

Regresyon katsayısı, x yani MANUEL istasyon ölçümünün her 1 $\mathrm{mm}$ artışında, OMGi istasyonundaki yağış miktarı artışını ifade etmektedir. Her iki istasyonun aynı ölçümü yapması durumunda bu değerin 1 olması beklenmektedir. Değerin 1'den uzak-

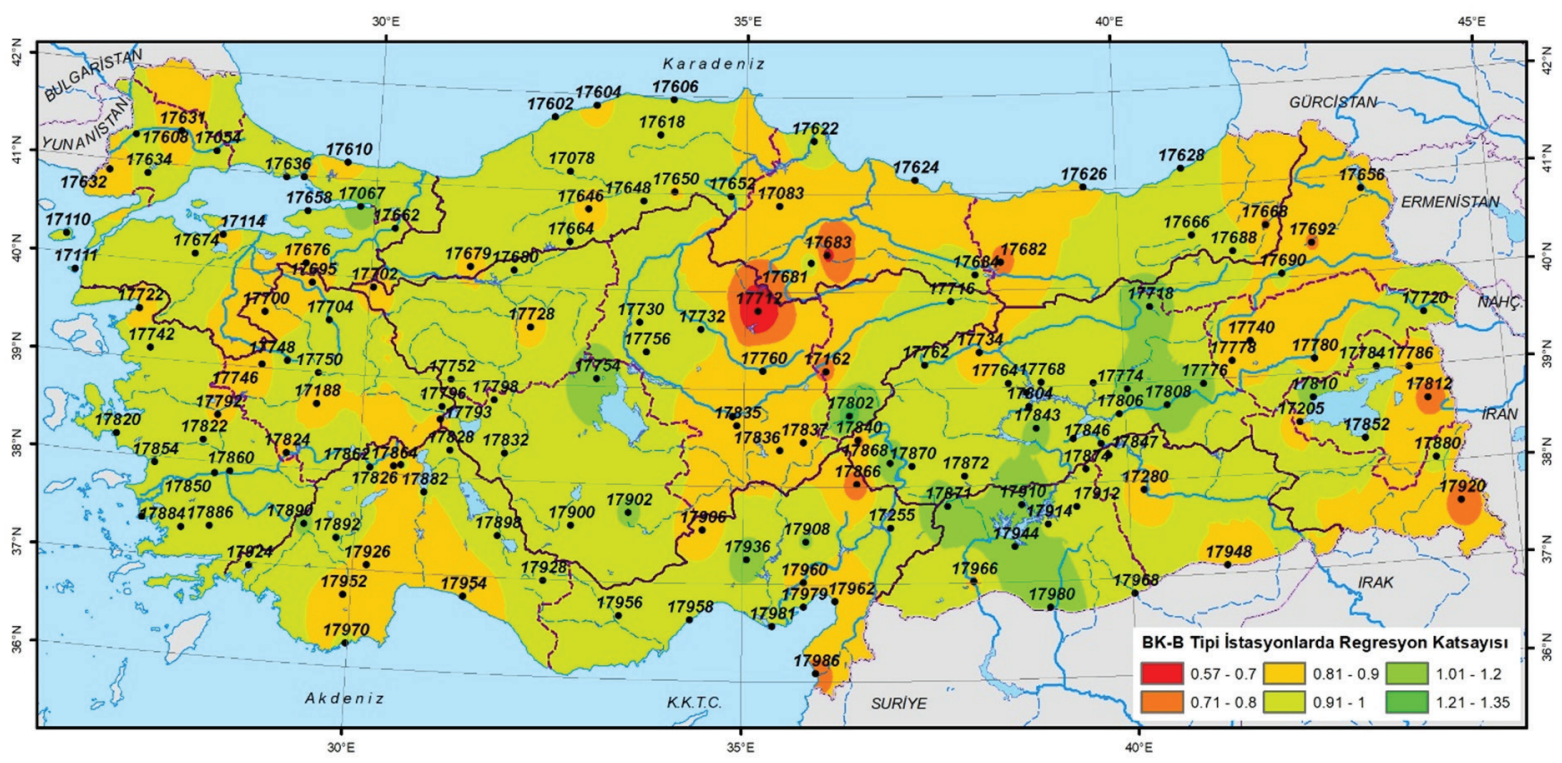

Şekil 9. Türkiye'de BK-B tipi istasyonların regresyon katsayısı dağılışı.

Figure 9. Regression coefficient distribution at BK-B type stations in Turkey. 

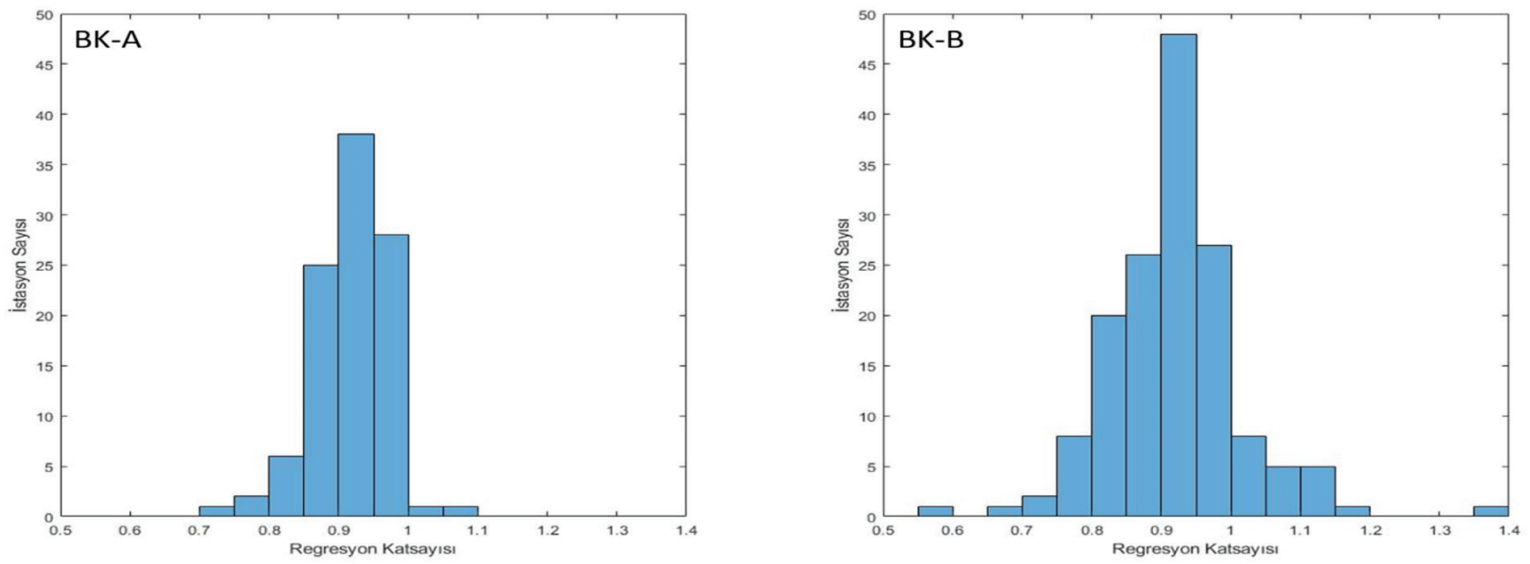

Şekil 10. BK-A ve BK-B tipi istasyonlarda regresyon katsayısı sıklık grafikleri.

Figure 10. Regression coefficient histograms at $B K-A$ and $B K-B$ type stations.

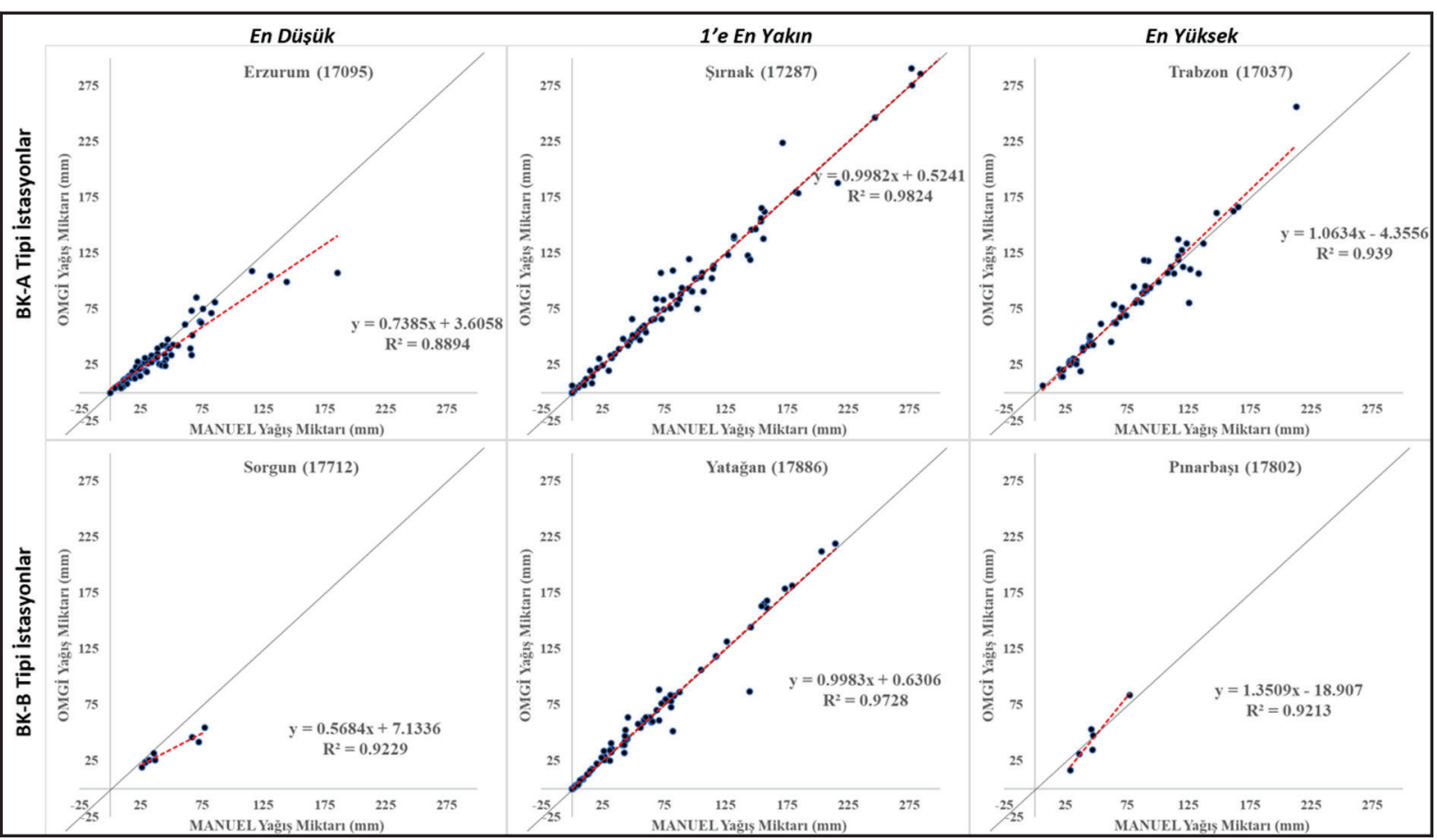

Şekil 11. BK-A ve BK-B tipi istasyonlarda 1'e en yakın, en yüksek ve en düşük regresyon katsayılarına sahip istasyonların regresyon modelleri ve grafikleri (Kırmızı kesikli çizgi regresyon doğrusunu, siyah sürekli doğru ise $45^{\prime}$ lik eğimi, 1 regresyon katsayısını temsil etmektedir).

Figure 11. Regression models and graphs of stations with the closest to 1 , highest and lowest regression coefficients at BK-A and BK-B type stations (Red dashed line represents regression line, black continuous line represents 45 slope $=1$ regression coefficient).

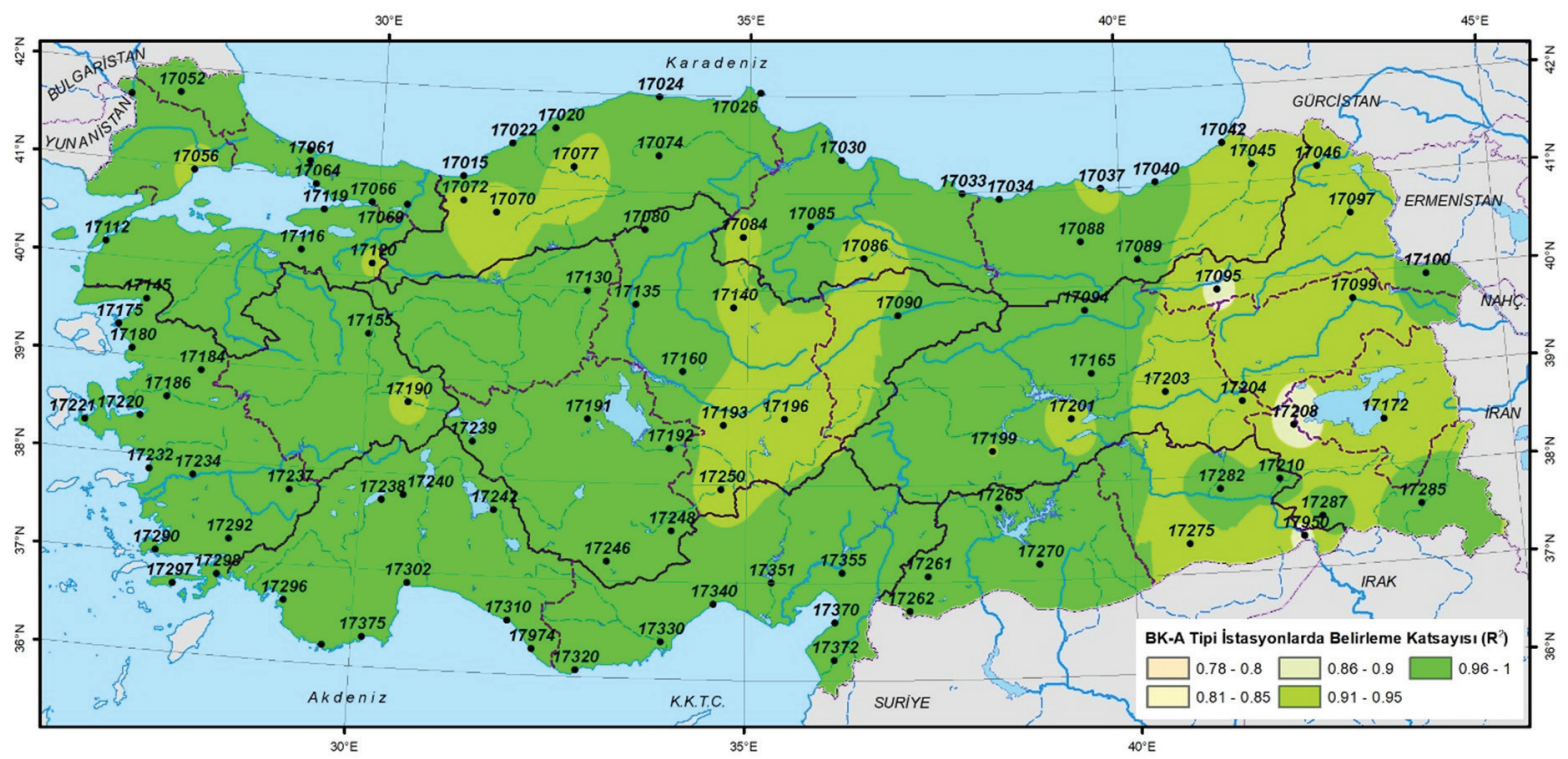

Şekil 12. Türkiye'de BK-A tipi istasyonların belirleme katsayısı dağılışı.

Figure 12. Coefficient of determination distribution of BK-A type stations in Turkey. 


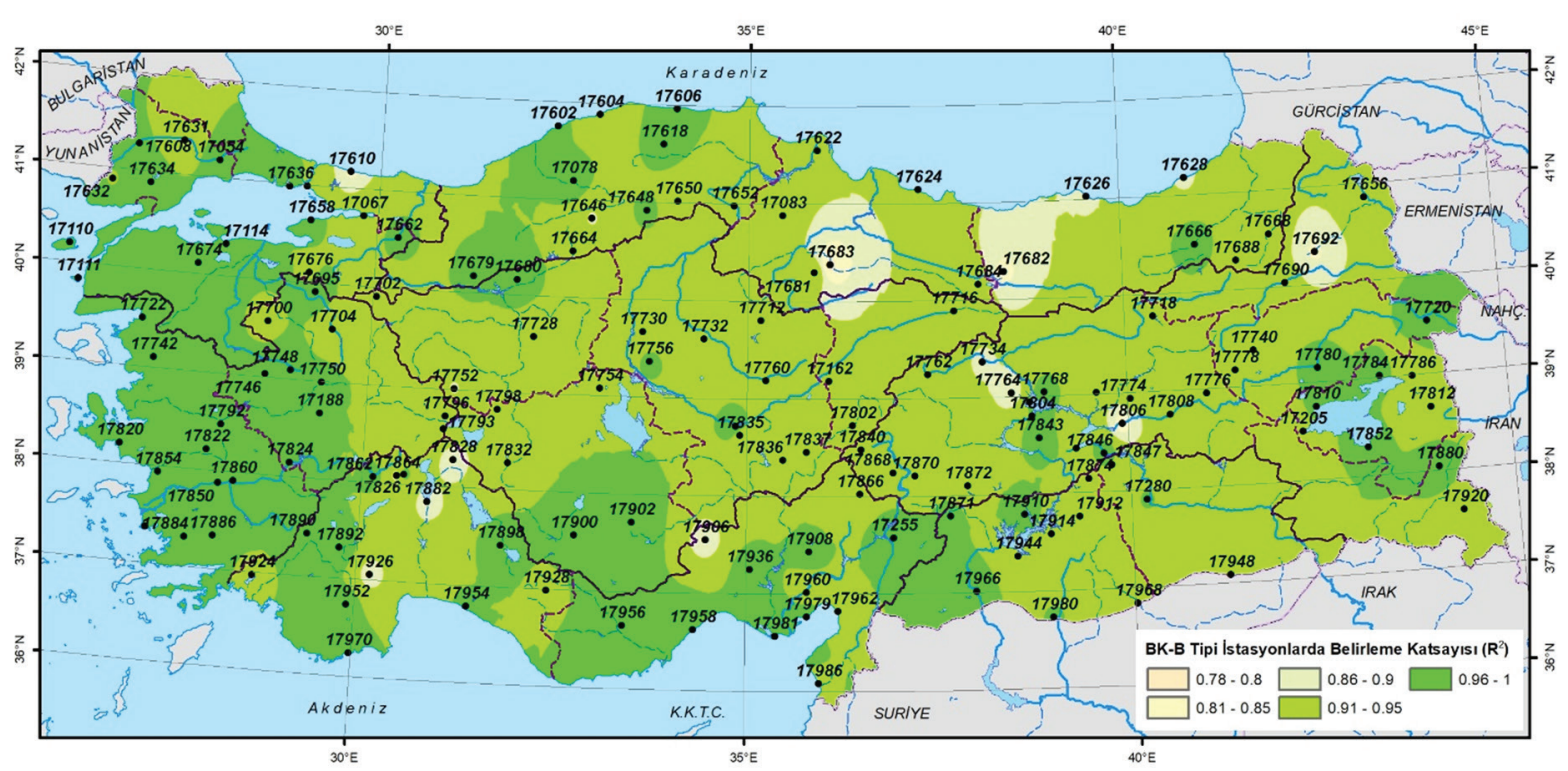

Şekil 13. Türkiye'de BK-B tipi istasyonların belirleme katsayısı dağılışı.

Figure 13. Coefficient of determination distribution of BK-B type stations in Turkey.

laşması, iki istasyon ölçümünün birbirine göre oranının değiştiğini, ölçüm farkının arttğını göstermektedir. Değerin 1'den büyük olması, MANUEL istasyonun OMGI'ye göre daha düşük değerler ölçtüğünü, 1'den daha küçük değerler ise, MANUEL istasyonun OMGi'ye göre daha yüksek değerler kaydettiğini göstermektedir. Her iki tip istasyonda da daha çok 1'den düşük katsayılar elde edilmesi, genel olarak MANUEL ölçümlerinin OMGi'lere göre yüksek çıktğını göstermektedir. Bu durumda, herhangi doğal bir eğilim olmasa bile, OMGi verilerinin MANUEL istasyon verisi devamı olarak kullanılması durumunda, regresyon sabitinin 1'den düşük olduğu sahalarda yağış düşüşü, 1'den yüksek sahalarda ise yağış artışı belirlenebilecektir. Bu farklılığın araştırmacılar tarafindan göz önünde bulundurulması gerekmektedir.

\subsection{Belirleme Katsayısı R'deki Değişim}

Analizler sonunda BK-A tipi istasyonlarda, belirleme katsayıları yüksek değerler göstermiş sadece 17208 (Bitlis), 17950 (Cizre) ve 17095 (Erzurum) istasyonlarında 0,9'dan düşük değerler elde edilmiştir (Şekil 12). İç Anadolu Bölgesinin doğusu ile Doğu ve Güneydoğu Anadolu Bölgelerinin doğu yarılarında düşük belirleme katsayıları hesap edilmiş, Türkiye'nin geriye kalan kısımlarında 0,95'ten yüksek değerler belirlenmiştir.

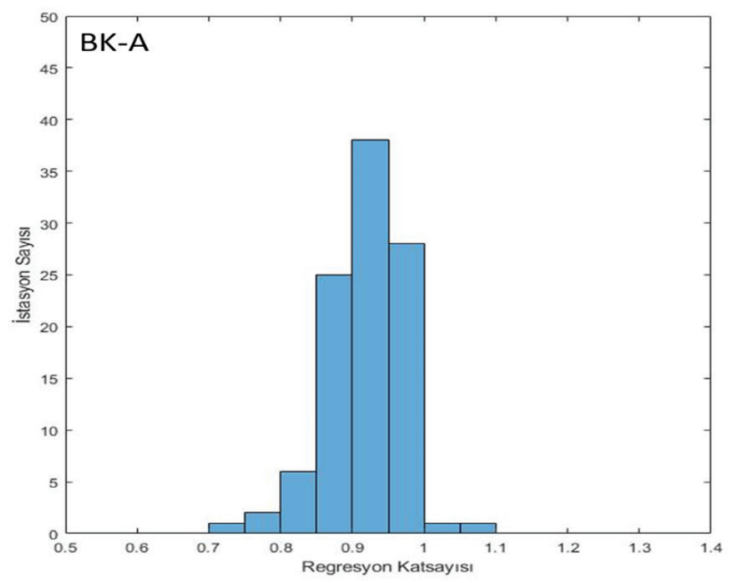

BK-B tipi istasyon verilerinin analizi sonucunda belirleme katsayıları, 0,783 ile 0,99 arasında değişmiş, ortalama olarak da 0,94 değeri elde edilmiştir. Belirleme katsayıları, Karadeniz, İç, Doğu ve Güneydoğu Anadolu Bölgelerinde düşük olarak belirlenmiş (Şekil 13) buna rağmen bu değerlere ait hipotez testlerinin tamamı BK-A tipi istasyonlarda olduğu gibi $p<0,001$ düzeyinde anlamlı çıkmıştır.

Hem BK-A hem de BK-B tipi istasyonların analizi neticesinde, belirleme katsayılarının sola çarpık dağılım gösterdiği, BK-B tipindeki dağılımın daha simetrik bir özellikte olduğu anlaşılmıştır (Şekil 14).

Analizler sonucunda BK-A tipi istasyonlarda en düşük belirleme katsayısı 0,8463 ile 17208 (Bitlis), en yüksek ise 0,9966 ile 17375 (Finike) istasyonunda belirlenmiştir (Şekil 15). 17208'de OMGi istasyonu MANUEL istasyona göre genelde daha düşük yağış değeri ölçerken, bazı durumlarda bu değer artmış, iki istasyon ölçümleri birbirinden farklı değerler göstermektedir. BK-B tipi istasyonlarda ise en düşük belirleme katsayısı 17683 (Turhal), en yüksek ise 17722 (Burhaniye) istasyonunda belirlenmiştir (Şekil 15). 17683'te düşük belirleme katsayısının hesaplanması, örneklem büyüklüğünden de kaynaklanmış, az sayıda ölçümle yapılan analiz neticesinde düşük değer elde edilmiştir.

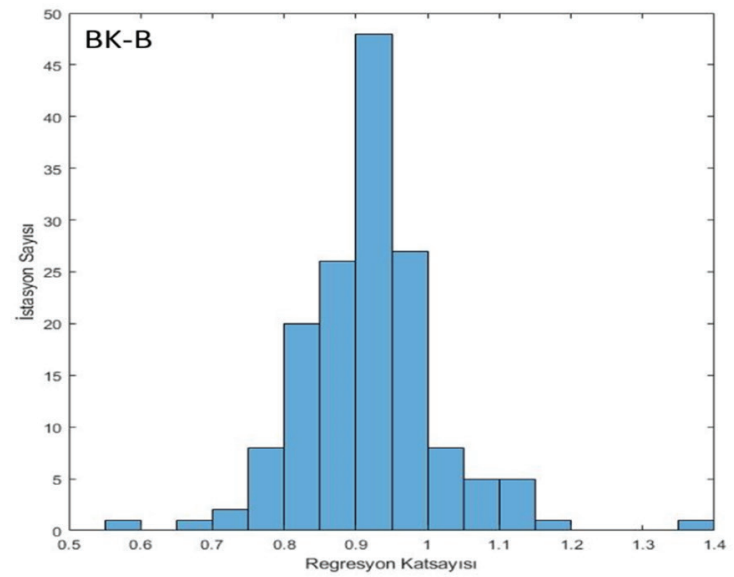

Şekil 14. BK-A ve BK-B tipi istasyonlarda belirleme katsayısı sıklık grafikleri.

Figure 14. Coefficient of determination histograms at $B K-A$ and $B K-B$ type stations. 


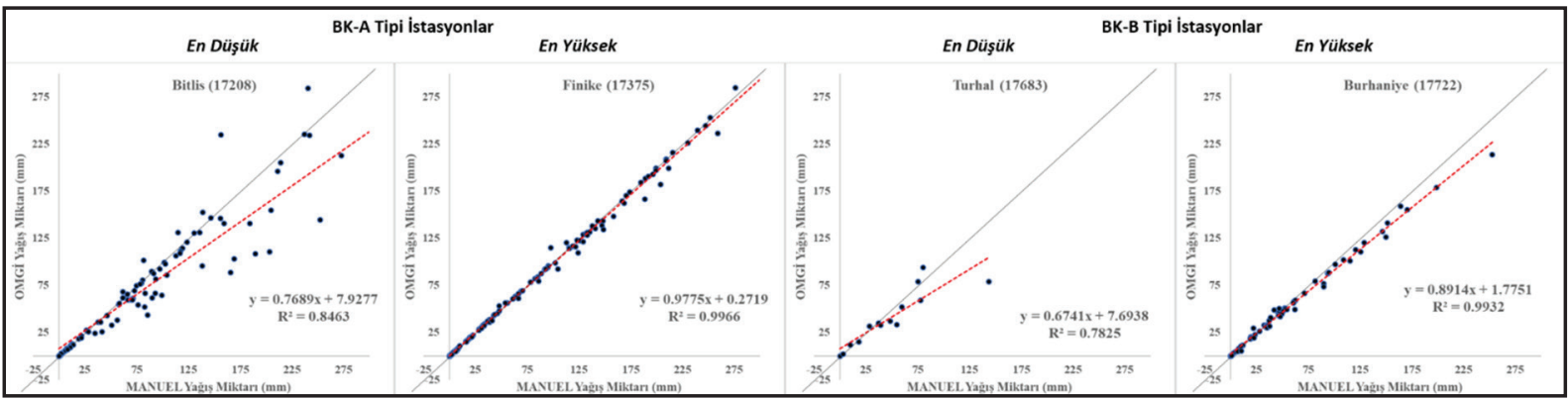

Şekil 15. BK-A ve BK-B tipi istasyonlarında en düşük ve en yüksek belirleme katsayısı elde edilen analizler.

Figure 15. Lowest and highest coefficient of determinations obtained from analysis at BK-A and BK-A type stations.

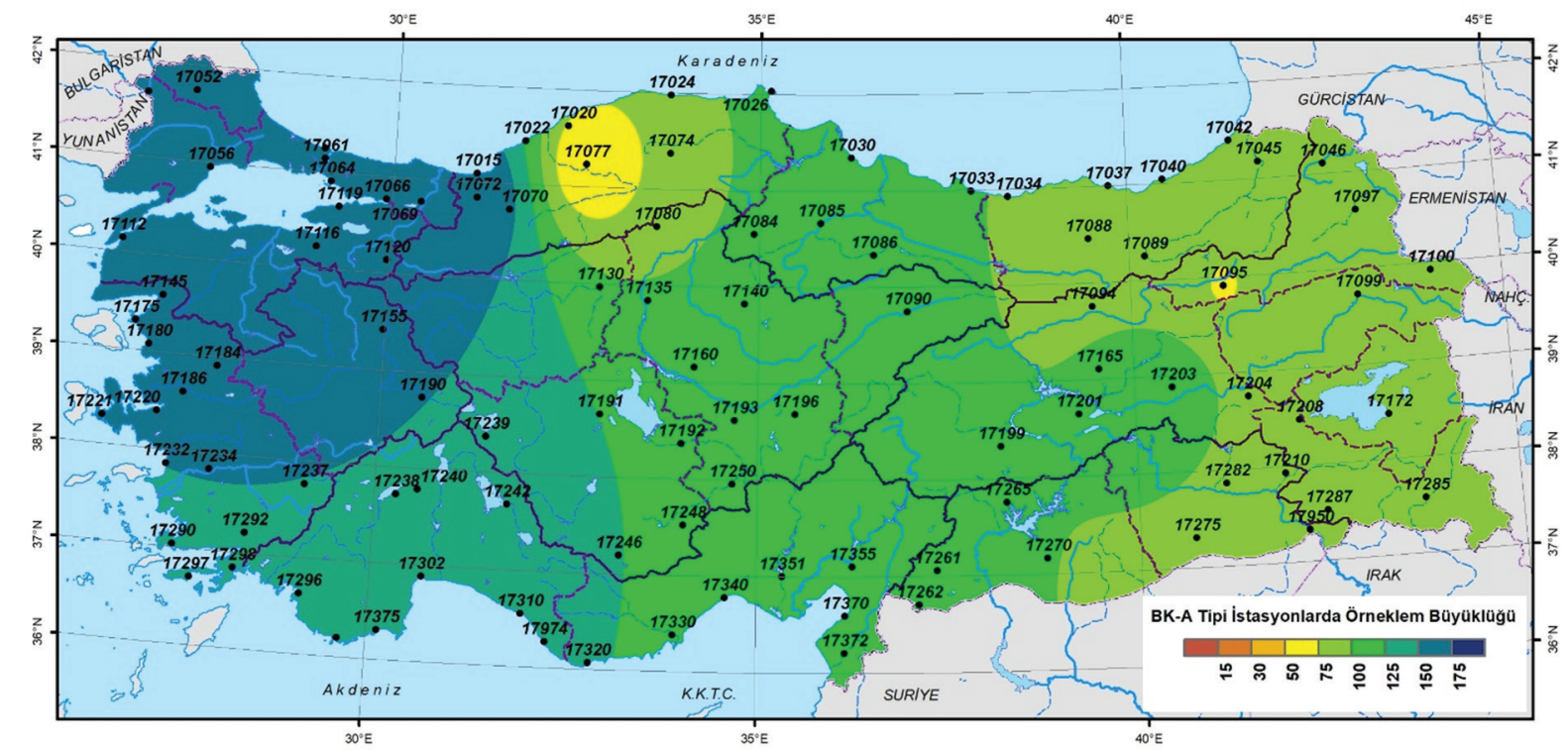

Şekil 16. Türkiye'de BK-A tipi istasyonların örneklem büyüklük dağılışı.

Figure 16. Distribution of sample size at BK-A type stations in Turkey.

Belirleme katsayısı, bağımsız değişkenin bağımlı değişken tarafından açıklanma oranı olarak tanımlanabilir. 1'e yaklaşan değerler, bağımız değişkenin bağımlı değişkence temsil edilme kabiliyetinin yüksek olduğunu göstermektedir. Buna rağmen bu değerin hipotez testi, analizde kullanılan N sayısına bağlıdır. 0,9 olarak belirlenebilecek bir değer, N sayısı düşük olduğunda anlamsız olabilmekte, 0,15 olarak belirlenen bir değer ise $\mathrm{N}$ sayısı büyük olduğunda anlamlı çıkabilmektedir. Yapılan analizlerde genel olarak belirleme katsayıları yüksek çıkmış, regresyon modellerinin kullanılabilir olduğu görülmüştür. Bu durumda, OMGi veri ölçümleri kullanılarak MANUEL ölçümleri, MANUEL ölçümler kullanılarak OMGi verilerini tahmin etmek mümkün olabilmektedir. Bu şekilde veri standardizasyonu sağlanabilecek, iki istasyon arasındaki farklılıkların giderilmesi mümkün olacaktır.

\subsection{Regresyon Analizi Sonuçları ile Örneklem Büyüklükleri Arasındaki ïlişkiler}

BK-A tip istasyonlarda analiz edilen N sayısı 55 ile 184 arasında değişmiş genel olarak Türkiye'nin batısında daha uzun rasat süresi nedeniyle yüksek $\mathrm{N}$ değerleri ortaya çıkmıştır (Şekil 16). OMGi'lerin ilk olarak Marmara Bölgesine kurulması nedeniyle bu bölgede $N$ değeri de yüksek olmakta, bu sahalardaki OMGi-MANUEL ölçümler arasındaki ilişkiler de daha doğru belirlenebilmektedir.
BK-B tipi istasyonlarda N sayısı 6 ile 125 arasında değişmiş ve Türkiye'nin doğusu ile batısı arasında bir asimetri oluşmuştur (Şekil 17). Bu ise eşzamanlı ölçümlerin Türkiye'nin doğu yarısında kısa, bat yarısında ise uzun bir dönem boyunca devam ettikten sonra sonlandırıldığını göstermektedir. Bu durum, doğudaki MANUEL ölçüm verilerinin OMGi standartlarına dönüştürülmesi esnasında dezavantajlar yaratabilecektir.

$\mathrm{N}$ değeri ile regresyon analizi sonuçları arasındaki ilişkiler incelenmek istendiğinde hem BK-A hem BK-B tipi istasyonlarda OMGi kurulma ve MANUEL istasyonla eşzamanlı çalıştırılma süreleri birbirine yakın olan ikişer grup ortaya çıkmıştır (Şekil 18a-f). Bu nedenle BK-A tipi istasyonlar 140, BK-B tipi istasyonlar ise 40 örneklem büyüklüğüne göre iki gruba ayrılmış birinci gruplar mavi, ikinci gruplar turuncu renk ile grafiklenmiştir. Bu gruplarda $\mathrm{N}$ değeri ile regresyon sabiti arasına ilişkilere bakıldığında (Şekil 18a, d), sadece BK-B tipi istasyonların ikinci grubunda N değeri artışının sabiti 0’a yaklaştırdığı görülmektedir. BK-B ve BK-A tipi istasyonların birinci grubunda regresyon sabiti değişkenliği fazladır. BK-A tipi istasyonların ikinci grubunda regresyon sabiti değişkenliği düşük olsa da $\mathrm{N}$ değeri ile sabit arasındaki ilişki belirgin değildir.

Hem BK-A hem de BK-B istasyonlarda N değeri arttıkça regresyon katsayısının 1'e yaklaştığı görülmektedir (Şekil 18b, e). BK-B istasyonların birinci grubunda N sayısının düşük 


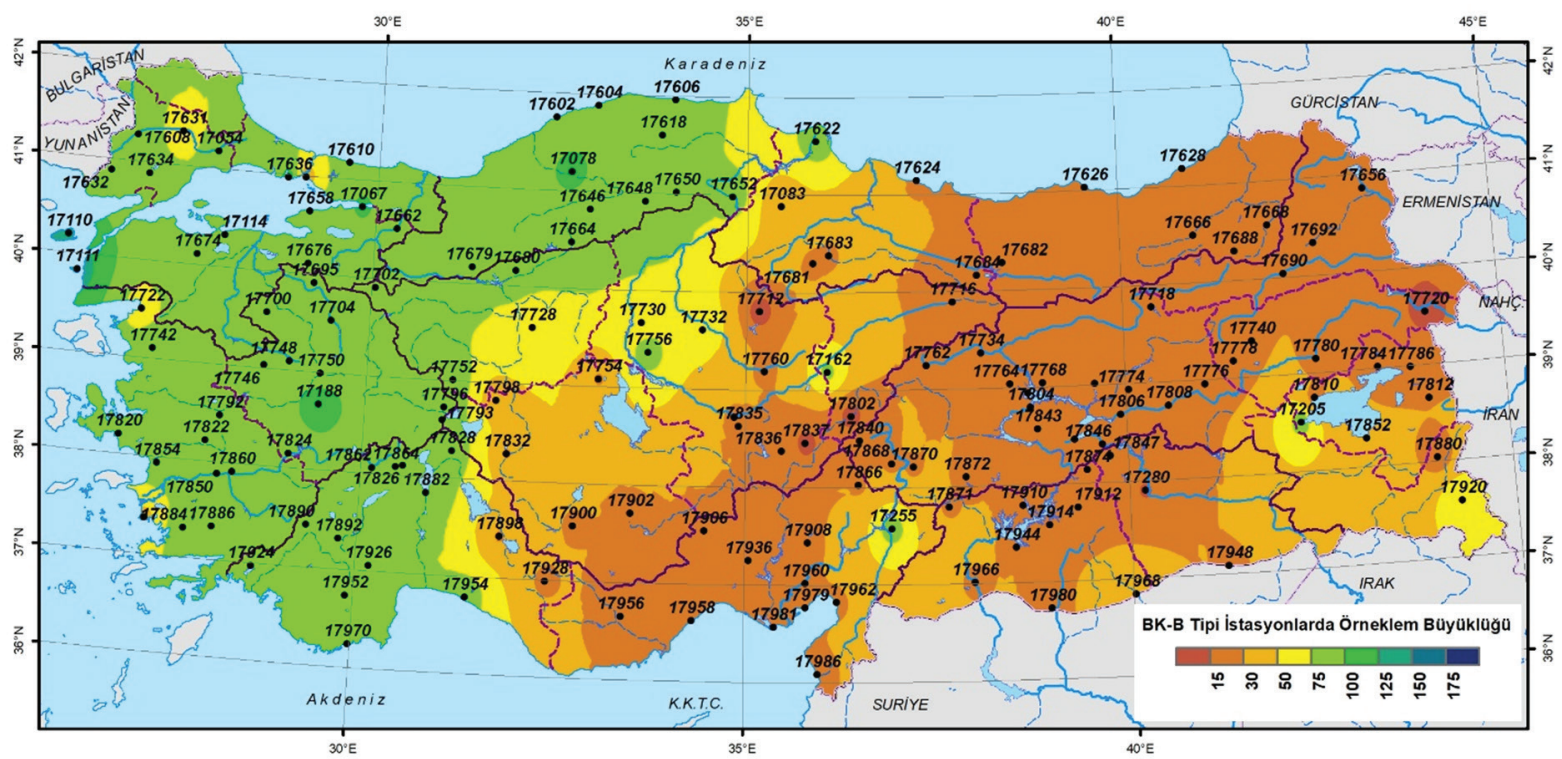

Şekil 17. Türkiye'de BK-B tipi istasyonların örneklem büyüklük dağılışı.

Figure 17. Distribution of sample size at BK-B type stations in Turkey.

olması, regresyon katsayısındaki değişkenliği artırmış, ikinci grubunda ise $\mathrm{N}$ değerinin artmasıyla genlik azalmıştır.

Her iki istasyon tipinde de $\mathrm{N}$ sayısı arttıkça belirleme katsayıları yükseltmekte, 1'e yaklaşmaktadır. Hem BK-A hem de BK-B tipi istasyonlardaki birinci grup, $N$ değeri düşük istasyonlardaki belirleme katsayısındaki değişkenlik daha fazla (Şekil 18c, f), N değeri ile ilişki daha düşüktür. BK-B istasyonların birinci grubunda bu durum daha belirgindir.

\section{Sonuç}

Türkiye'de 2000'li yıllardan sonra faaliyete geçen OMGi istasyonları sürekli artmakta, dağlık alanlara da kurul- maya başlanmaktadır. MANUEL ve OMGi istasyonlarının eşzamanlı çalıştırıldığı dönemlerde, birbirine yakın yağış değerleri ölçmüşler, buna rağmen ölçüm değerleri arasında farklılıklar oluşmuştur. Bu farklı ölçümler arasında veri standardizasyonu problemi bulunmakta, bu problemlerin tanımlanması ve çözüme kavuşturulması gerekmektedir.

Regresyon analizi neticesinde, BK-A ve BK-B tipi istasyonlarda belirlenen regresyon sabitleri 0'dan farklı çıkmıştır. Bu durum, düşük yağışlı aylarda (regresyon sabitlerine göre yaklaşık 0-20 mm), aynı yağışı ölçen iki farklı istasyonun farklı değerler kaydettiği ve mutlak sıfırlarının birbiriyle aynı olmadığını göstermektedir. Bu farklılık nedeninin belirlenmesi gerekmektedir.
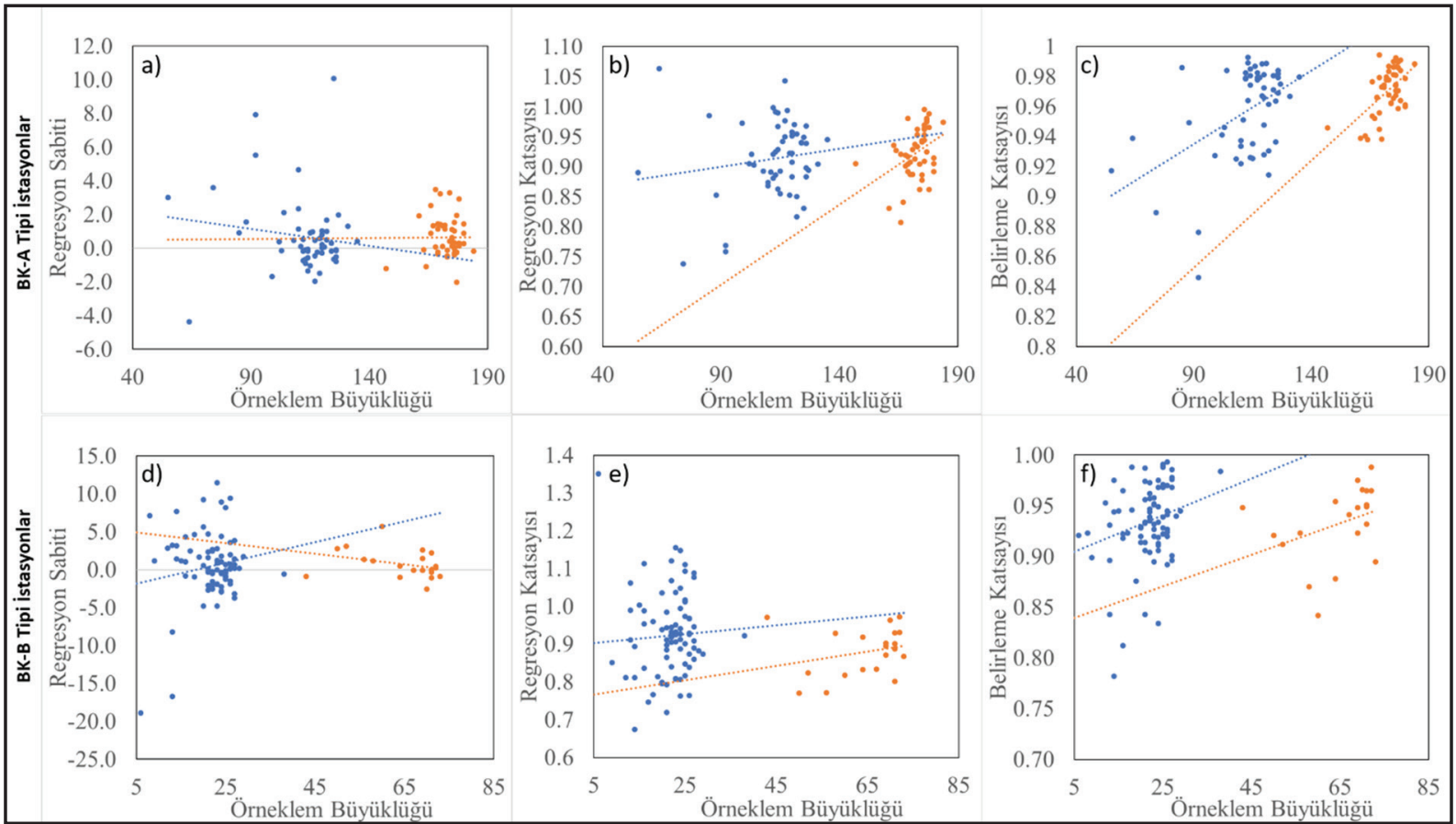

Şekil 18. Örneklem büyüklükleri ile regresyon analizi sonuçları arasındaki ilişkiler.

Figure 18. Relationship between sample sizes and regression analysis results. 
Analizler sonucunda elde edilen regresyon katsayıları hem BK-A hem de BK-B tipi istasyonlarda 1'den uzaktır. Bu durum, regresyon sabitinde olduğu gibi, MANUEL ve OMGi istasyonları arasında bire bir ilişki olmadığını göstermektedir. Genel olarak 1'den düşük çıkan regresyon katsayıları, Türkiye genelinde MENUEL istasyonların OMGi'lere göre yüksek ölçümler yaptığını göstermektedir. Bu farklı ölçümler, OMGi istasyonu verisinin MANUEL ölçüm verisinin devamı olarak kullanılamayacağını göstermektedir. Bu problemin ortadan kaldırılması için, farklı yağış ölçümü nedenleri her istasyonda ayrı ayrı analiz edilmeli ve OMGI verileri MANUEL istasyon verilerine göre standart hale getirilmeli, yağış zaman serileri sürekliliği sağlanmalıdır.

BK-A tipi istasyonların bir kısmında belirleme katsayısı düşük çıkmış, Türkiye genelinde ise örneklem büyüklüğü artışına bağlı olarak yüksek değerler belirlenmiştir. Buna rağmen BK-B tipi istasyonlardaki belirleme katsayıları düşüktür. Bu da BK-B tipi istasyon verilerinin güvenilirliklerini düşürmektedir. Genel olarak belirleme katsayıları, N sayısına bağlı olarak yükselmektedir. Örneklem genişliği yüksek olan istasyonlar için belirlenen değerler daha yüksek ve güvenilir sonuçlar vermektedir. Bu nedenle, MGM tarafından mümkünse BK-B tipi istasyonlarda sonlandırılan MANEUL ölçümler tekrar başlatılmalı, regresyon parametreleri daha güvenilir bir şekilde belirlenmelidir. BK-A istasyonlarında ise daha güvenilir, tutarlı ölçümler elde edilene dek hem MANUEL hem de OMGi ölçümler yapılmalı, bu istasyonların Türkiye iklimi için temel istasyonlar olduğu göz önünde bulundurulmalı, mümkünse manuel ölçümler sürekli devam ettirilmelidir.

Çalışma esnasında, grafiklenerek incelenen MANUEL ve OMGI verilerinin 100 mm'nin üstünde yağış düşen aylarda aynı olmadığı, bazı istasyonlarda ve zamanlarda OMGI, bazı dönemlerde ise MANUEL yağış verilerinin yüksek olduğu görülmüştür. Bu durum bu çalışmada incelenmemesine rağmen, ileride yapılacak analizlerde problem yaratacak sonuçlar doğurabilecektir. Bu ölçüm farklılıklarının nedenleri üzerine de çalışılmalı ve ölçümler tutarlı hale getirilmelidir. Bu çalışmada analizler aylık yağış toplamları için yapılmış, farklılıklar belirlenmeye çalışılmıştır. Bu işlemlerin günlük ve saatlik yağışlara da yapılması gerekmektedir. MGM tarafından kurulacak bir komisyon-araştırma grubu tarafından bu analizler yapılmalı, veri standardizasyonu sağlanmalıdır.

MANUEL ve OMGi istasyonlarındaki ölçüm farklılıklar birçok nedenden kaynaklanıyor olabilir. Bunlar içerisinde gün boyunca düşen yağışın MANUEL istasyonlarda ertesi gün sabah kontrol edilerek kayıt altına alınması durumunda (özellikle yazın) düşük yağışlı günlerde bu yağışın buharlaşmaya maruz kalması ve düşük yağış kaydedilmesi, OMGi istasyonlarının katı yağışları ölçerken belli bir ısıtma kullanması ve bu ısıtmanın ise buharlaşma riski taşıması, OMGi'lerin bakımlarının gecikmesine bağlı olarak plüviyometrelerde oluşan çevresel-beklenmeyen problemlerin (örneğin kuşların plüviyometre ağzını doldurması, yağış yönüne engelleyici yapı inşa edilmesi, ) zamanında giderilememesi, OMGi'lerdeki plüviyometrelerin kalibrasyon eksiklikleri, hassasiyet farklılıkları ve MANUEL istasyonlarda insan kaynaklı ölçüm hataları sayılabilmektedir. Bu ihtimallerin standardizasyon esnasında göz önünde bulundurulması önerilmektedir.

Analizler başlangıcında, bazı ayların yağış verilerinin olmadığı görülmüştür. Akdeniz iklimine sahip bölgelerde haziran-eylül arasında yağış kaydedilmemesi normaldir. Fakat bazı durumlarda, bir istasyonun en yağışlı olduğu ayın yağış verilerinde de eksiklikler görülmüştür. Bu durumda eksik verinin düzenlenmesi ile ilgili problemler doğmakta, hangi ayda yağış olmadığı hangi ayda kayıt tutulmadığı anlaşılamamaktadır. MGM tarafından bu karışıklığı giderecek bir yöntem geliştirilmeli, yağış düşmeyen aylar "0", yağışı verisi kaydedilmeyen aylar ise "eksik" şeklinde düzenlenmelidir.

\section{Kaynakça}

Akçakaya, A., Demircan, M., Sümer, M. U., \& Şensoy, S. (2013). iklim gözlemlerinin doğruluğu ile devamlıı̆ını etkileyen faktörler ve türdeşlik testleri. Meteoroloji Genel Müdürlüğü.

Alpar, R. (2003). Uygulamalı çok değişkenli istatistiksel yöntemlere giriş 1. Nobel Yayın Dağıtım.

Çiçek, i. (2001). Türkiye'de günlük yağış şiddetleri ve frekansları. Ankara Üniversitesi Türkiye Coğrafyası Araştırma ve Uygulama Merkezi Dergisi, 8, 27-48.

Dadaser-Çelik, F., Cengiz, E., \& Güzel, Ö. (2016). Trends in reference evapotranspiration in Turkey: 1975-2006. International Journal of Climatology, 36(4), 1733-1743. https://doi.org/10.1002/ joc. 4455

Erlat, E. (1996). Türkiye'de günlük yağışların şiddeti üzerine bir inceleme. Ege Coğrafya Dergisi, 9(1996), 159-184.

Gürtan, K. (1979). Istatistik ve araştırma metodları. Fatih Yayınevi Matbaası.

Içcel, G., \& Ataol, M. (2014). Türkiye'de yıllık ortalama sicakliklar ile yağışlarda eğilimler ve NAO arasında ilişkileri (1975-2009). Coğrafya Dergisi, 28, 55-68.

Koç, T., \& Keskin, N. (2001). Uzunköprü'de halk takvimi ve sıcaklık ilişkisi. Balıkesir Üniversitesi, Sosyal Bilimler Dergisi, 5, 1-15.

Meteroloji Genel Müdürlüğü. (2020a). Türk Meteroloji Tarihi. Meteroloji Genel Müdürlüğü. https://mgm.gov.tr/genel/meteorolojitarihi.aspx

Meteroloji Genel Müdürlüğü. (2020b). Türkiye Meteorolojik Gözlem Sistemleri İstatistiksel Analizleri 1970-2019. Meteroloji Genel Müdürlüğü. https://www.mgm.gov.tr/FILES/resmi-istatistikler/ gozlemSistemleri/Turkiye-Meteorolojik-Gozlem-Sistemleri.pdf

Sencer, M., \& Sencer, Y. (1978). Toplumsal araştirmalarda yöntembilim. Türkiye ve Orta Doğu Amme İdaresi Enstitüsü Yayınları.

Tekin, M. K., Tatlı, H., \& Koç, T. (2018, Ekim 3-6). Türkiye'deki yaşam-bölgelerinin Holdridge yaşam-zon yöntemi ile belirlenmesi. Içinde N. Türkoğlu, R. Bayar, K. Karabacak, C. K. Anlı, H. Kılar, E. Gökkaya (Eds.), TÜCAUM 30. yıl uluslararası coğrafya sempozyumu bildiriler kitabı (ss. 713-722). Türkiye Coğrafyası Araşttrma ve Uygulama Merkezi. http://tucaum.ankara.edu.tr/tucaum-30-yil-uluslararasi-cografya-sempozyumu-bildiriler-kitabi/ 
Toros, H. (2012). Spatio-temporal precipitation change assessments over Turkey. International Journal of Climatology, 32(9), 13101325. https://doi.org/10.1002/joc.2353

Türkeş, M. (2003) Spatial and temporal variations in precipitation and aridity index series of Turkey. İçinde Bolle H.J. (Ed), Mediterranean Climate. Regional Climate Studies Kitabı (ss.181-213). Springer.

Türkeş, M., Sümer, U. M., \& Kiliç, G. (2002). Persistence and periodicity in the precipitation series of Turkey and associations with $500 \mathrm{hPa}$ geoptential heights. Climate Research, 21(1), 59-81. https://doi:10.3354/cr021059

Türkeş, M., \& Tatli, H. (2009). Use of the standardized precipitation index (spi) and a modified spi for shaping the drought probabilities over Turkey. International Journal of Climatology, 29(15), 2270-2282. https://doi.org/10.1002/joc.1862
Türkeş, M. (1996). Spatial and temporal analysis of annual rainfall variations in Turkey. International Journal of Climatology, 16(9), 1057-1076. https://doi.org/10.1002/(SICI)1097-0088(199609)1 6:9<1057::AID-JOC75>3.0.CO;2-D

Weisberg, S. (2015). Aplplied linear regression (Fourth edition.). John Wiley \& Sons.

Yılmaz, E. (2018). Türkiye'de aylık yağış eğilimleri, yağış kaymaları ve yağış eğilim rejimleri. Journal of Human Sciences, 15(4), 20662091. https://doi:10.14687/jhs.v15i4.5479

Yılmaz, E., \& Çiçek, ì. (2016). Türkiye Thornthwaite iklim sınıflandırması. Journal of Human Sciences, 13(3), 3973-3993. https:// doi:10.14687/jhs.v13i3.3994 